\title{
The HPx software for multicomponent reactive transport during variably-saturated flow: Recent developments and applications
}

\author{
Diederik Jacques $^{1 *}$, Jiří Šimůnek ${ }^{2}$, Dirk Mallants ${ }^{3}$, Martinus Th. van Genuchten ${ }^{4,5}$ \\ ${ }^{1}$ Engineered and Geosystems Analysis Unit, Belgian Nuclear Research Centre, 2400 Mol, Belgium. \\ ${ }^{2}$ Department of Environmental Sciences, University of California Riverside, Riverside, CA 92521, USA. E-mail: jsimunek@ucr.edu \\ ${ }^{3}$ CSIRO, Urrbrae, SA 5064, Australia. E-mail: dirk.mallants@csiro.au \\ ${ }^{4}$ Center for Environmental Studies, CEA, São Paulo State University, Rio Claro, SP 13506-900, Brazil. \\ E-mail: rvangenuchten@hotmail.com \\ ${ }^{5}$ Department of Nuclear Engineering, Federal University of Rio de Janeiro, Rio de Janeiro, RJ, 21945-970, Brazil. \\ * Corresponding author. E-mail: diederik.jacques@sckcen.be
}

\begin{abstract}
HPx is a multicomponent reactive transport model which uses HYDRUS as the flow and transport solver and PHREEQC-3 as the biogeochemical solver. Some recent adaptations have significantly increased the flexibility of the software for different environmental and engineering applications. This paper gives an overview of the most significant changes of HPx, such as coupling transport properties to geochemical state variables, gas diffusion, and transport in two and three dimensions. OpenMP allows for parallel computing using shared memory. Enhancements for scripting may eventually simplify input definitions and create possibilities for defining templates for generic (sub)problems. We included a discussion of root solute uptake and colloid-affected solute transport to show that most or all of the comprehensive features of HYDRUS can be extended with geochemical information. Finally, an example is used to demonstrate how HPx, and similar reactive transport models, can be helpful in implementing different factors relevant for soil organic matter dynamics in soils. HPx offers a unique framework to couple spatial-temporal variations in water contents, temperatures, and water fluxes, with dissolved organic matter and $\mathrm{CO}_{2}$ transport, as well as bioturbation processes.
\end{abstract}

Keywords: HYDRUS; HPx; Numerical modeling; Reactive transport; Organic matter; Bioturbation.

\section{INTRODUCTION}

Mathematical, process-based simulation models are indispensable tools for elucidating the role of coupled processes in soil systems, including their functioning and providing ecosystem services (Vereecken et al., 2016). Coupled multicomponent reactive transport models for the so-called critical zone (Brantley et al., 2007) are essential tools to analyze nonlinear interactions between hydrological, geochemical and (micro)biological processes and to link the critical zone to other spheres of the earth system such as the hydrosphere, atmosphere, biosphere, and geosphere (Li et al., 2017; Steefel et al., 2005). During the last two decades, a number of tools have been developed to simulate such coupled processes in natural subsurface and engineered systems (Steefel et al., 2015). Numerous applications illustrate the enormous possibilities of these codes (e.g., see references in Li et al. (2017), Steefel et al. (2015)). They typically couple a water flow equation (such as the Richards equation for the vadose zone) with transport equations for heat and solutes based on the advection-dispersion equation, a thermodynamically based geochemical solver, and a kinetic reaction solver, while allowing for the coupling of multiple parameters with a series of state variables (Figure 1). Because of the generic nature of such codes, they provide a flexible (in terms of model formulations) and extendible (in terms of model components) problem-solving environment to tackle important environmental and engineering problems. This paper focuses on the HPx simulator as developed within the HYDRUS computer software packages (Šimůnek et al., 2016). In this introduction we first introduce briefly two aspects which illustrate the need for such modeling tools.

Reactive transport models allow for the direct coupling of time-varying geochemical state variables with transport proper- ties. In addition to the coupling of microstructural changes due to mineral dissolution and precipitation to porosity and hydraulic properties (Freedman et al. (2004), Wissmeier and Barry (2009), Xie et al. (2015)), fluid properties such as viscosity and density, which are linked to the hydraulic properties of porous media, depend upon the composition of the aqueous solution (Laliberté (2007), Laliberté and Cooper (2004), Sharqawy et al. (2010)). Biomass accumulation or biofilm production during microbiological reactions can also induce changes in hydraulic properties, which may potentially influence the coupled hydrological-physical-geochemical-biological processes operative in porous media and, consequently, such processes as flow paths, the performance of biofilters, and the transport of colloids (e.g., Bozorg et al. (2015a), Bozorg et al. (2015b), Carles Brangarí et al. (2017), Or et al. (2007), Rockhold et al. (2002), Yarwood et al. (2006)). The processes of precipitation and dissolution of minerals may be affected by microbiological processes, such as in the engineering practice of microbially induced calcium carbonate precipitation (Hommel et al., 2015; Martinez et al., 2014). Another process that can produce changes in porosity and the hydraulic properties is the migration of fines (solid mineral particles), which is influenced by both hydrodynamic and chemical factors (Bennacer et al., 2017; Mays and Hunt, 2007; Yu et al., 2013). Again, this process is relevant in many engineering applications, but also within the field of soil development. Finally, under saturated conditions, biogenic processes such as methanogenesis and denitrification may result in the formation of gas bubbles, which may result in a reduction of the hydraulic conductivity due to blocking of pore spaces (Amos and Mayer, 2006).

Organic matter dynamics in soils is a crucial process affecting many environmentally-related issues. Degradation produces inorganic carbon, which can be released into the atmosphere. 


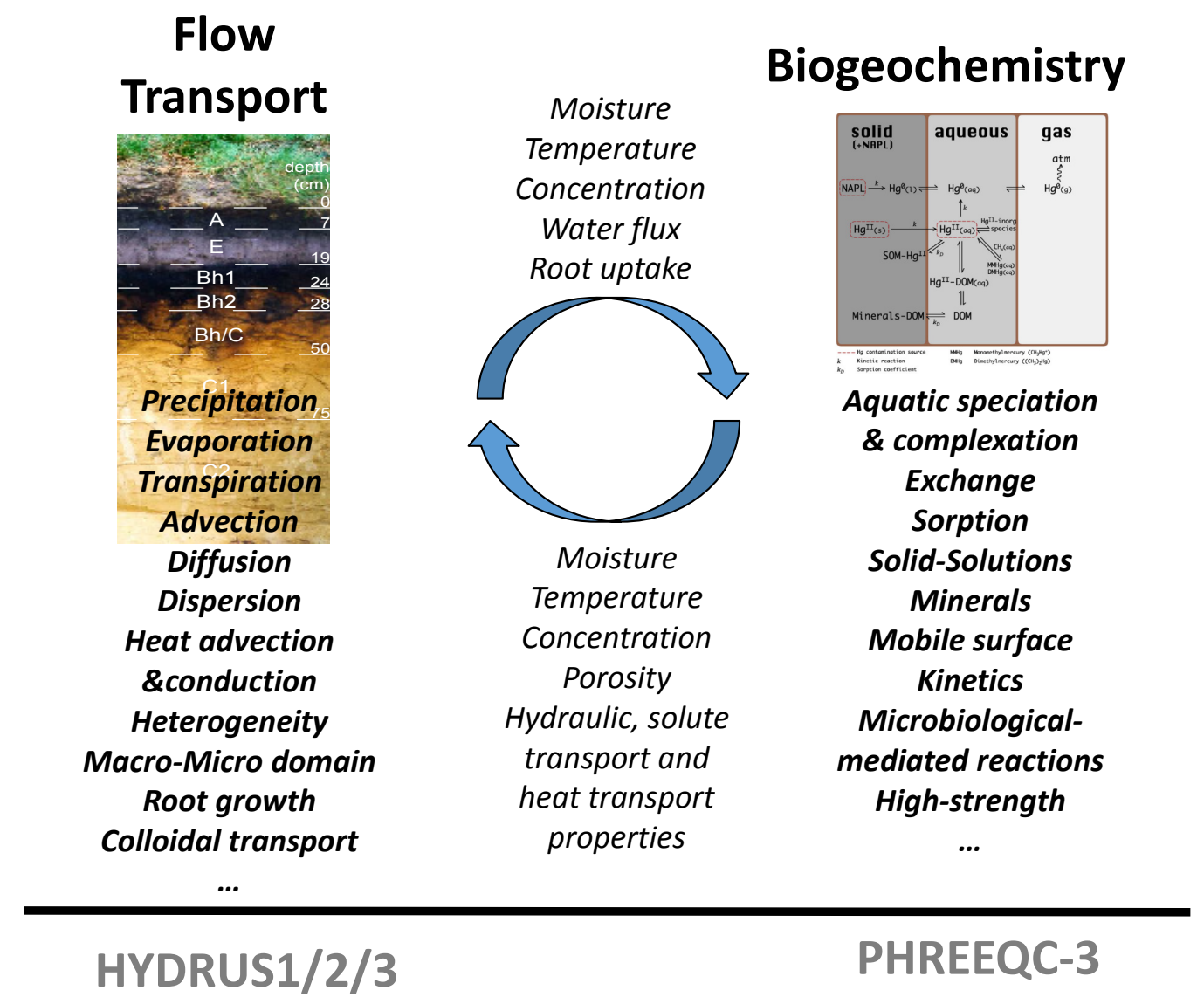

Fig. 1. Reactive transport models coupling water flow and solute transport with biogeochemical processes.

Consequently, $\mathrm{CO}_{2}$ sequestration in soils may be a factor in controlling atmospheric $\mathrm{CO}_{2}$, and thus climate change (ToddBrown et al., 2013). And vice versa, climate change, together with land use, influences soil organic matter (SOM) dynamics (e.g. Batlle-Aguilar et al. (2011)). Dissolved organic matter (DOM) plays also an important role in many soil processes including contaminant transport (e.g., Maes et al. (2006), Paradelo et al. (2012)). For example, Leterme and Jacques (2015) showed that DOM concentrations are among the most sensitive factors in simulating $\mathrm{Hg}$ fate in soil systems.

As reported by Manzoni and Porporato (2009), a large number of models exist for simulating SOM dynamics. Many SOM models are so-called compartment models, which divide the heterogeneous nature of SOM into a number of homogeneous pools, and then simulate the fluxes between these pools. Some of these models have a rigid structure in the sense that the number of pools, the abiotic factors that must be considered, their functional forms, and the extent of biotic-abiotic interactions, are fixed. It is therefore not always possible to perform a structured comparison between different types of model formulations. Reactive transport models, on the other hand, provide a flexible structure that enables the introduction of different SOM degradation networks within the same simulation framework. In addition, existing compartment models sometimes strongly simplify flow and transport processes and/or the geochemistry involved, such as simplifying or ignoring $\mathrm{pH}$ and buffering effects on degradation or $\mathrm{CO}_{2}$ geochemistry. For predictions that are more accurate, also within the framework of climate predictions, SOM models should consider temporarily and spatially variable abiotic factors such as temperature and moisture, nutrient dynamics, microbial activity, solid-water interac- tions, and transport processes of solid and dissolved organic matter and/or inorganic carbon (e.g., Schmidt et al. (2011), Tang and Riley (2015)). Reactive transport models should account for these factors and effects, such as illustrated in recent studies by Tang et al. (2013) and Riley et al. (2014).

The main objective of this paper is to give an overview of new capabilities of the HPx codes compared to the model descriptions given previously by Jacques et al. (2006) and Jacques et al. (2008a). We also wanted to illustrate some of these capabilities as used in several recent studies, as well as present an example involving different SOM degradation networks and bioturbation processes.

\section{THE HPX REACTIVE TRANSPORT CODE}

The HPx codes couple the HYDRUS-1D and HYDRUS (2D/3D) software packages (Šimůnek et al., 2016) with PHREEQC (Parkhurst and Appelo, 2013) using a sequential non-iterative coupling approach as explained by Jacques et al. (2006). HYDRUS-1D or HYDRUS (2D/3D) act as the solver for the hydrological and physical processes, including variablesaturated water flow, solute transport, diffusion in the gas phase, and heat transport, whereas PHREEQC is the solver for thermodynamic and kinetic geochemical processes. While the first versions of HPx used PHREEQC-2.4 (Jacques and Šimůnek, 2005; Jacques et al., 2006), the most recent versions 2.4 of HPx use PHREEQC 3.1. Two- and three dimensional flow and transport is included as well (Šimůnek et al., 2012).

Coupling with PHREEQC is performed using so called "hard coupling", which is in principle similar to the procedures available in the more recently developed wrappers iPhreeqc 


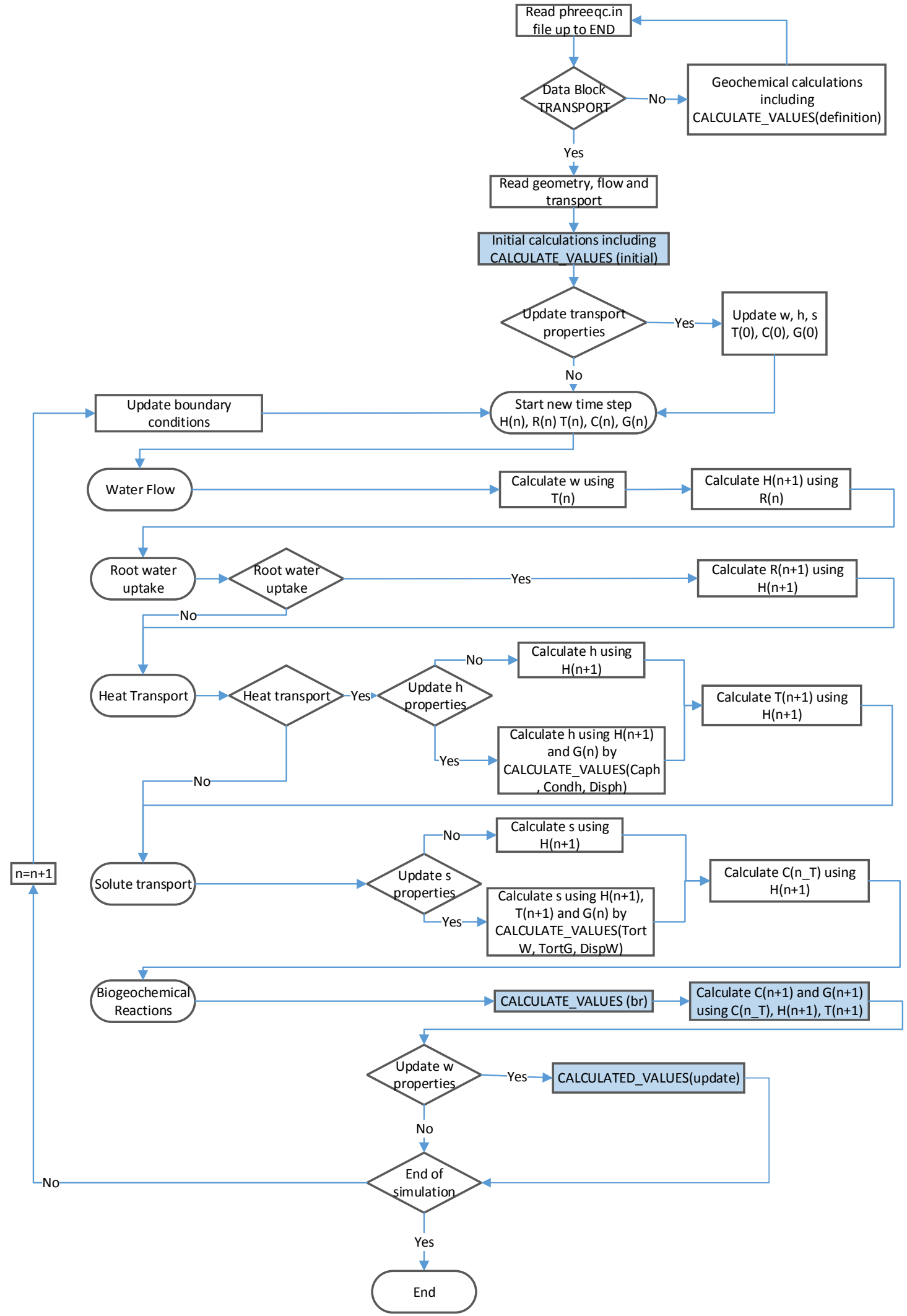

Fig. 2. Flow chart of HPx. The letters $w$, h, and s indicate parameters for water flow, heat transport, and solute transport, respectively. The variables $\mathrm{H}, \mathrm{R}, \mathrm{T}, \mathrm{C}$, and $\mathrm{G}$ indicate state variables for water flow, root water uptake, heat transport, solute transport, and biogeochemical processes, respectively. The boxes with blue background are steps run in parallel using OpenMP. CALCULATED_VALUE(type) indicates the execution of scripts labeled with type.

(Charlton and Parkhurst, 2011) and RMPhreeqc (Parkhurst and Wissmeier, 2015). Due to the hard coupling, HPx does not always include the latest version of PHREEQC. However, HPx includes additional flexibilities compared to the original
PHREEQC, such as linking geochemical definitions (e.g., solution compositions, exchange sites, minerals, kinetic reactants) to the material distribution, or exchanging information between the flow model and the BASIC scripts (e.g., pressure heads, 
velocities, and scaling factors). The geochemical input is defined using the standard PHREEQC input conventions using data blocks and identifiers, thereby allowing a direct implementation of the PHREEQC models into HPx. The scripting possibilities are now enhanced by introducing global variables or data tables, which can be used as inline variables or as BASIC scripting variables, using different types of scripting blocks to perform specific calculations, and introducing a specific version of BASIC (such as MyBasic; https:/github.com/paladint/my_basic) with structured grammar for some specific calculations). Templates for generic types of problems can be generated in advance and then imported into additional input files that can be created during project execution using the INCLUDE\$ statement. Geochemical calculations are performed in parallel using the OpenMP (www.openmp.org) shared memory approach and PHREEQC objects. The main object reads then the input and performs all initial calculations. The information (thermodynamic data and geochemical models) is copied to a user-defined number of additional objects representing chunks in the OpenMP formalism. The nodes are assigned evenly between the chunks. A dynamic schedule controls the calculations of the nodes in a chunk on the available threads on a computer. After the geochemical calculations, the information from different chunks is assembled and sent to the transport calculations or to the model output files. Because of the OpenMP implementation and the enhanced scripting possibilities, the current flow chart of HPx (see Figure 2) is an extended version of the chart described in Jacques et al. (2006).

Simulation output data now also contain variables, which are integrated over a part of the domain, such as over a particular soil material. HP2 makes it possible to obtain geochemical information along mesh lines or cross-sections at different times as defined in the standard HYDRUS (2D/3D) graphical user interface.

\section{FLOW, TRANSPORT, AND BIOGEOCHEMICAL PROCESSES \\ Conceptual models}

Figure 3 shows schematically the different physical water flow and solute transport models implemented in HPx. The software considers flow, transport, and the prevailing biogeo-
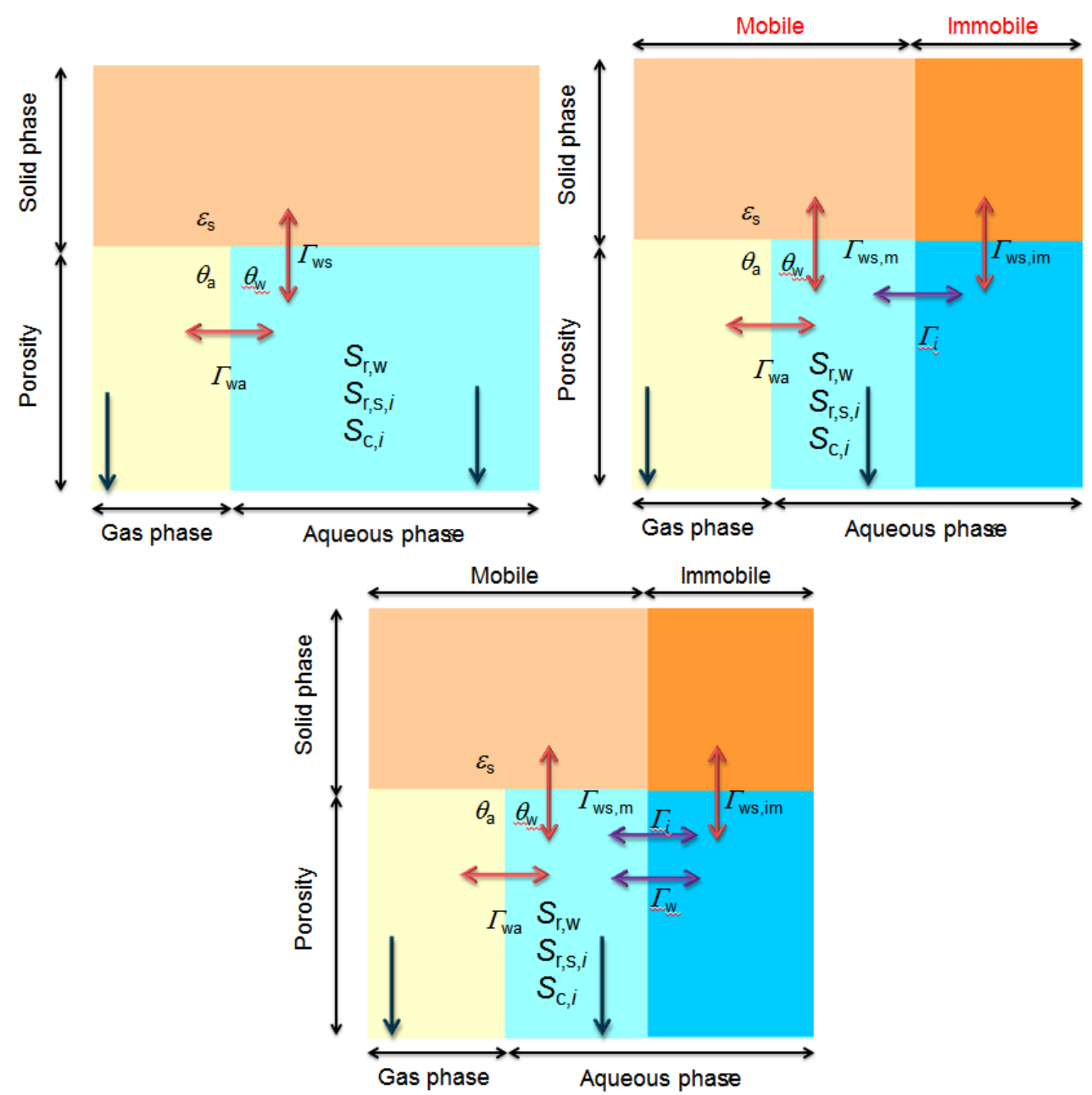

Fig. 3. Conceptual physical and geochemical models implemented in HPx. Black arrows represent transport processes within a single phase, and red arrows exchange processes between different phases. The top left, top right, and bottom plots indicate water flow, solute transport, and biogeochemical reactions in a single-porosity continuum, in a single-porosity continuum with an immobile solute domain, and in a dual-porosity model, respectively $\left(\varepsilon_{s}\right.$ - the solid content $\left[\mathrm{dm}^{3} \mathrm{dm}^{-3}\right], \theta_{a}$ - the air content $\left[\mathrm{dm}^{3} \mathrm{dm}^{-3}\right], \theta_{w}-$ the water content $\left[\mathrm{dm}^{3} \mathrm{dm}{ }^{-3}\right]$, $\Gamma_{w}$ - the water exchange between the immobile and mobile domains $\left[\mathrm{dm}^{3} \mathrm{dm}^{-3} \mathrm{~T}^{-1}\right] \Gamma_{w a}$ - the solute exchange between the aqueous phase and the gas phase $\left[\mathrm{mol} \mathrm{dm}{ }^{-3} \mathrm{~T}^{-1}\right], \Gamma_{w s}$ - the solute exchange between the aqueous phase and the solid phase $\left[\mathrm{mol} \mathrm{dm}^{-3} \mathrm{~T}^{-1}\right], \Gamma_{w s, m}-$ the solute exchange between the mobile aqueous phase and the solid phase $\left[\mathrm{mol} \mathrm{dm}^{-3} \mathrm{~T}^{-1}\right], \Gamma_{w s, i m}$ - the solute exchange between the immobile aqueous phase and the solid phase $\left[\mathrm{mol} \mathrm{dm} \mathrm{T}^{-3} \mathrm{~T}^{-1}\right], \Gamma_{i}$ - the solute exchange between the immobile and mobile domains $\left[\mathrm{mol} \mathrm{dm}^{-3} \mathrm{~T}^{-1}\right], S_{r, w}-\operatorname{root}$ water uptake $\left[\mathrm{dm}^{3} \mathrm{dm}^{-3} \mathrm{~T}^{-1}\right], S_{r, s, i}-$ root solute uptake $\left[\mathrm{mol} \mathrm{dm} \mathrm{T}^{-1}\right], S_{c, i}-$ kinetic transformations in the aqueous phase $\left.\left[\mathrm{mol} \mathrm{dm}^{-3} \mathrm{~T}^{-1}\right]\right)$. 
chemical processes at the continuum scale with three main phases being water $\left(\theta_{\mathrm{w}}\right)$, air $\left(\theta_{\mathrm{a}}\right)$ and the solid phase $\left(\varepsilon_{\mathrm{s}}\right)$ as shown in the figure. The water and solid phases in the dual porosity modeling options of the code are divided into two parts, with one part comprising the mobile phase in which water, heat and solutes are allowed to move, and another part being the immobile domain where water is assumed to be stagnant.

Variably-saturated water flow, multicomponent solute transport and heat transport are described using the Richards equation, the advection-dispersion equations (for multiple solutes), and (neglecting energy transported by vapor transport) the convection-dispersion equation, respectively. Transport of reactive gases, which is crucial for simulating biological processes or solid phase alterations such as carbonation of concrete (e.g., Phung et al., 2016) or weathering ( $\mathrm{Li}$ et al., 2017), is either only by diffusion or advection. The latter is based on the assumptions of negligible air compressibility due to the fast exchange with the atmosphere, zero air flux at the bottom of the profile, and immediate matching of volume changes in the total water content by volume changes in the gas content.

Possible sinks of water in the flow domain are uptake by plants roots $\left(S_{\mathrm{r}, \mathrm{w}}\right)$ and exchange between the mobile and immobile water phases $\left(\Gamma_{w}\right)$, the latter only if dual-porosity water exchange is considered. Sinks or sources of solutes from the aqueous phase are via (i) exchange with roots $\left(S_{\mathrm{r}, i}\right.$ with $i$ referring to a solute component), (ii) kinetic transformations such as radioactive decay, degradation, or redox reactions $\left(S_{\mathrm{c}, i}\right)$, (iii) exchange between the mobile and immobile water phases $\left(\Gamma_{i}\right)$, and (iv) exchange with the gaseous $\left(\Gamma_{\mathrm{wa}}\right)$ or solid phases $\left(\Gamma_{\mathrm{ws}, \mathrm{m}}\right.$ and $\left.\Gamma_{\mathrm{ws}, \mathrm{im}}\right)$ via thermodynamic speciation reactions or kinetic rate equations. The latter reactions represent processes such as sorption, ion exchange, surface complexation, gas-aqueous phase equilibria, and mineral dissolution and precipitation.

\section{Mathematical models}

Water flow in its most general form is described using a dual-porosity formulation of the Richards equation (Šimůnek and van Genuchten, 2008):

$$
\begin{aligned}
& \frac{\partial \theta_{\mathrm{m}}}{\partial t}=\frac{\partial}{\partial x_{i}}\left[K\left(K_{i j}^{A} \frac{\partial h}{\partial x_{j}}+K_{i z}^{A}\right)\right]-S_{\mathrm{r}, \mathrm{w}}-\Gamma_{w} \\
& \frac{\partial \theta_{\mathrm{im}}}{\partial t}=\Gamma_{w}
\end{aligned}
$$

where $\theta_{\mathrm{m}}$ is the volumetric water content in the mobile domain $\left[\mathrm{L}^{3} \mathrm{~L}^{-3}\right], \theta_{\mathrm{im}}$ is the volumetric water content in the immobile domain $\left[\mathrm{L}^{3} \mathrm{~L}^{-3}\right], h$ is the pressure head [L], $x_{i}(i=1,2,3)$ are the spatial coordinates [L], $t$ is time [T], $S_{\mathrm{r}, \mathrm{w}}$ is the root water uptake term $\left[\mathrm{T}^{-1}\right], \Gamma_{\mathrm{w}}$ is the water exchange term $\left[\mathrm{T}^{-1}\right]$ driven by a first-order rate equation proportional to the difference in water contents or pressure heads between the mobile and immobile domains, $K_{i j}^{A}$ are components of a dimensionless anisotropy tensor $\boldsymbol{K}^{A}$, and $K$ is the unsaturated hydraulic conductivity function $\left[\mathrm{LT}^{-1}\right]$. The single-porosity models assume that $\theta_{\mathrm{m}}$ is equal to the total water content $\theta$, in which case $\theta_{\text {im }}$ and $\Gamma_{\mathrm{m}}$ become equal to zero. The second part of Eq. (1) for the immobile region then does not apply.

Several analytical forms are available to describe the unsaturated soil hydraulic properties $\theta(h)$ and $K(h)$ including Brooks and Corey (1964), van Genuchten (1980), Kosugi (1996), and Durner (1994). Root water uptake is driven by potential transpi- ration. Actual transpiration is calculated based on the spatialtemporal root distribution, while stress factors in the soil are linked to local water contents and salinities. The codes may be used to account for root water uptake compensation by allowing the roots to take up more water in less stressed soil zones (Šimůnek and Hopmans, 2009). Boundary conditions are either system-independent (e.g., constant or variable pressure head (Dirichlet), flux (Neumann), or gradient boundary conditions) or system-dependent by considering atmospheric conditions involving time-dependent precipitation, potential evaporation, and potential transpiration rates.

Heat transport is described as:

$C_{\mathrm{s}}(\theta) \frac{\partial T}{\partial t}=\frac{\partial}{\partial x_{i}}\left(\lambda_{i j}(\theta) \frac{\partial T}{\partial x_{i}}\right)-C_{w} q_{i} \frac{\partial T}{\partial x_{i}}$

where $C_{\mathrm{s}}$ and $C_{\mathrm{w}}$ are volumetric heat capacities $\left[\mathrm{ML}^{-1} \mathrm{~T}^{-2} \mathrm{~K}^{-1}\right]$ of soil and water, respectively, and $\lambda_{i j}$ is the apparent thermal conductivity of the soil $\left[\mathrm{MLT}^{-3} \mathrm{~K}^{-1}\right]$. The reactive module uses temperature to correct equilibrium constants or change rate coefficients as desired using user-defined relations. Equation (2) is valid for both single- and dual-porosity flow models when assuming local temperature equilibrium, i.e., that temperature is the same in the solid phase, as well as in the mobile and immobile liquid phases.

Solute concentrations in the aqueous phase are expressed in terms of total concentrations for a given primary species $C_{k}$ $(\mathrm{mol} / \mathrm{kgw})$, which includes the concentration of all aqueous equilibrium species, $c_{l}(\mathrm{~mol} / \mathrm{kgw})$ or so-called secondary species:

$C_{k}=c_{k}+\sum_{l=1}^{N_{a}} v_{l k} c_{l}$

where $v_{l k}$ is the stoichiometric coefficient of species $k$ in secondary species $l, k=1, \ldots, N_{\mathrm{c}}\left(N_{\mathrm{c}}\right.$ is the number of primary species) and $l=1, \ldots, N_{\mathrm{a}}\left(N_{\mathrm{a}}\right.$ is the number of secondary species). For each primary species, solute transport in the aqueous phase is described using advection-dispersion-reaction equations of the form:

$$
\begin{aligned}
& \frac{\partial \theta_{\mathrm{m}} C_{\mathrm{m}, k}}{\partial t}=\frac{\partial}{\partial x_{i}}\left(\theta_{\mathrm{m}} D_{i j}^{\mathrm{w}} \frac{\partial C_{\mathrm{m}, k}}{\partial x_{i}}\right)-\frac{\partial q_{i} C_{k}}{\partial x_{i}}-S_{\mathrm{r}, \mathrm{w}} C_{\mathrm{r}, k} \\
& -\Gamma_{k}-\Gamma_{\mathrm{wa}, k}-R_{\mathrm{m}, k}^{\mathrm{eq}}-R_{\mathrm{m}, k}^{\mathrm{kin}} \\
& \frac{\partial \theta_{\mathrm{im}} C_{\mathrm{im}, k}}{\partial t}=\Gamma_{k}-R_{\mathrm{im}, k}^{\mathrm{eq}}-R_{\mathrm{im}, k}^{\mathrm{kin}} \\
& \Gamma_{k}=\omega\left(C_{\mathrm{m}, k}-C_{\mathrm{im}, k}\right)+\Gamma_{\mathrm{w}}\left(H\left(\Gamma_{\mathrm{w}}\right) C_{\mathrm{m}, k}+H\left(-\Gamma_{\mathrm{w}}\right) C_{\mathrm{im}, k}\right)
\end{aligned}
$$

where $C_{\mathrm{m}, k}$ and $C_{\mathrm{im}, k}$ are the total concentrations of the $k$ species in the mobile and immobile domains $\left[\mathrm{mol} / \mathrm{dm}^{3}\right]$, respectively, $\theta_{\mathrm{m}}$ and $\theta_{\mathrm{im}}$ have the unit $\left[\mathrm{dm}^{3} / \mathrm{dm}^{3}\right], D^{\mathrm{w}}{ }_{i j}$ is the dispersion coefficient tensor $\left[\mathrm{L}^{2} \mathrm{~T}^{-1}\right], q_{i}$ is the $i$ th component of the Darcian fluid flux density $\left[\mathrm{LT}^{-1}\right], \mathrm{C}_{\mathrm{r}, k}$ is the concentration of the sink term $\left[\mathrm{mol} / \mathrm{dm}^{3}\right], \Gamma_{k}$ represents solute exchange between the immobile and mobile domains $\left[\mathrm{mol} / \mathrm{dm}^{3} \mathrm{~T}^{-1}\right], \Gamma_{\text {wa, } k}$ accounts for the exchange between the aqueous and the gas phase $\left[\mathrm{mol} / \mathrm{dm}^{3} \mathrm{~T}^{-1}\right], R_{\mathrm{m}, k}^{\mathrm{eq}}, R_{\mathrm{im}, k}^{e q}, R_{\mathrm{m}, k}^{\mathrm{kin}}$ and $R_{\mathrm{m}, k}^{\mathrm{kin}}$ are aqueous sink/source terms $\left[\mathrm{mol} / \mathrm{dm}^{3} \mathrm{~T}^{-1}\right]$, with the superscripts eq and kin referring to equilibrium and kinetic reactions, respectively, and subscripts $\mathrm{m}$ and im to the mobile and immobile domains, respectively, $\omega$ is the mass transfer coefficient $\left[\mathrm{T}^{-1}\right]$ and $\mathrm{H}()$ is the Heaviside step function. 
Reactive gases such as $\mathrm{O}_{2}$ and $\mathrm{CO}_{2}$ play important roles in many soil processes (e.g., pyrite oxidation, Mayer et al. (2015), and hence must form an integral part of reactive transport models. Diffusion in the gas phase is described as:

$$
\frac{\partial \theta_{\mathrm{a}} C_{\mathrm{a}, k}}{\partial t}=\frac{\partial}{\partial x_{i}}\left(\theta_{\mathrm{a}} D_{i j}^{\mathrm{a}} \frac{\partial C_{\mathrm{a}, k}}{\partial x_{i}}\right)+\Gamma_{\mathrm{wa}, k}
$$

where $C_{\mathrm{a}, k}$ is the concentration in the gas phase of component $k$ $\left[\mathrm{mol} / \mathrm{dm}^{3}\right], D_{i j}^{\mathrm{a}}$ is the gaseous diffusion tensor $\left[\mathrm{L}^{2} \mathrm{~T}^{-1}\right]$, and other symbols as defined before.

The geochemical model calculates aqueous concentrations of the primary and secondary species using an aqueous equilibrium chemical model written as:

$$
A_{l} \rightleftharpoons \sum_{k=1}^{N_{\mathrm{c}}} v_{l k} A_{k}
$$

where $A_{l}$ and $A_{k}$ are the chemical formulae of the species, $v_{l k}$ are stoichiometric coefficients and $N_{\mathrm{c}}$ is the number of primary species. Mass action laws permit calculations of the aqueous concentrations as follows:

$$
c_{l}=\frac{\prod_{k=1}^{N_{\mathrm{c}}}\left(\gamma_{k} c_{k}\right)^{v_{l k}}}{K_{l} \gamma_{l}}
$$

where $K_{l}$ is the equilibrium constant for the reaction, defined as product of the activities of the reaction products divided by the product of the activities of the reactants, and $\gamma_{i}$ and $\gamma_{j}$ are the activity correction coefficients to obtain activity $a[-]$ when multiplied with $c$. The thermodynamic constants are adapted for temperature using the enthalpy of the reaction in the van't Hoff equation or by a six-term analytic equation as a function of temperature (Parkhurst and Appelo (2013), see e.g. also Eq. (2) in the appendix). Some of the parameters of this equation can be linked to thermodynamic variables, such as the change of entropy, enthalpy and heat capacity of reaction, at least for relatively small temperature variations (e.g., Puigdomènech et al. (1997), Jacques (2009)) that are expected for soil conditions. Several activity correction models are implemented, such as ion-association models (Davies equation, extended DebyeHûckel equation), Pitzer model, and a model based on specific ion interaction theory (SIT). Ion exchange, surface complexation, mineral, gas-aqueous phase and solid solutions equilibrium models are available heterogeneous reactions to calculate the $\Gamma_{\mathrm{wa}, k}, R_{\mathrm{m}, k}^{\mathrm{eq}}$ and $R_{\mathrm{im}, k}^{e q}$, terms in Eq. (4).

Equilibrium between the gas and aqueous phases is given as:

$$
G_{l} \rightleftharpoons A_{l}
$$

where $G_{l}$ is the chemical formula of the gaseous component. The equilibrium constant of the reactions is the ratio of the activity of $A_{l}$ over the fugacity of $G_{l}$. With the assumption of an ideal gas phase, which is valid for low total gas phase pressures, the fugacity coefficient is 1 in which case the fugacity equals the partial pressure of $G_{l}$. Fugacity correction factors can be calculated with the Peng and Robinson equation of state (Peng and Robinson, 1976). However, for total gas phase pressures lower than $10 \mathrm{~atm}$, the fugacity coefficient will be close to 1 (Appelo et al., 2014).

A general ion exchange reaction in which the site capacity is always occupied by ions of the opposite charge (i.e., a charge neutral reaction) is given as:

$v_{X_{k}} X_{k}+v_{l} A_{l} \rightleftharpoons v_{X_{l}} X_{l}+v_{k} A_{k}$

where $X$ denotes the chemical formula of an exchange species and $v$ is the stoichiometric coefficient, which is linked to a thermodynamic constant using different conventions for the activity correction of the exchange species including GainesThomas, Gapon, and Vanselow convention. The RothmundKornfeld equations (Bloom and Mansell, 2001; Bond, 1995), allows one to consider the effects of a changing selectivity with site occupancy (e.g., Jacques et al. (2012)). Different exchange sites can be combined to define a multisite exchange model (e.g., Jacques et al. (2008b)).

A general equation for surface complexation is:

$S^{z_{s}}\left(A_{k}^{z_{k}}\right)_{v_{k}}+v_{l} A_{l}^{z_{l}} \rightleftharpoons S^{z_{s}}\left(A_{l}^{z_{l}}\right)_{v_{l}}+v_{k} A_{k}^{z_{k}}$

where $S$ represents the chemical formula of a surface master species, and $z$ the charge of the surface master species, the aqueous species, or the complexed species. Chemical equilibrium is obtained when the ratio of the activity product is equal to the equilibrium reaction constant, possibly corrected for electrostatic effects. These effects can be either neglected using a non-electrostatic model or incorporated by using a diffuse double layer model (Dzombak and Morel, 1990) or the CDMUSIC model (Hiemstra and VanRiemsdijk, 1996). The composition of the double layer to counterbalance the surface is estimated by explicitly calculating the charge distribution in the layer (Borkovec and Westall, 1983) or by the Donnan model (Appelo and Wersin, 2007).

A general mineral dissolution/precipitation reaction is of the form:

$M_{l} \rightleftharpoons \sum_{k=1}^{N_{l}} v_{k l} A_{k}$

where $M$ represents the chemical formula of the mineral and $N_{1}$ the number of aqueous species in the reaction equation. Since the activity of a pure phase (mineral) is assumed to be equal to 1 , the equilibrium constant is the activity product of the aqueous species. In ideal solid solutions, which are homogeneous mixtures of different minerals, the activity of the phase is less than 1, leading to a more stable phase compared to the pure phase. For non-ideal binary solid solutions, described using the Guggenheim series expansion model (Guggenheim, 1937), a mechanical mixture may sometimes be more stable than the homogeneous mixture, resulting in an immiscibility gap or phase separation.

The $R_{\mathrm{m}, k}^{\mathrm{kin}}$ and $R_{\mathrm{m}, k}^{\mathrm{kin}}$ terms in Eq. (4) represents homogeneous and heterogeneous kinetically controlled reactions, respectively. Homogeneous reaction networks may involve redox, degradation or decay reactions. Each species in such a degradation network must be treated as primary species for which a separate transport equation is required. Typical heterogeneous reactions are dissolution and precipitation of minerals, for which different kinetic expressions exist. One group is based on transition state theory (Aagaard and Helgeson, 1982), which allows for irreversible reactions; the rate parameter may depend on solution composition variables such as $\mathrm{pH}$ or activities of other species, which could act as catalyzer or inhibitor. However, irreversible rate equations based on a shrinking core model (e.g., Liu et al. (2014)) or equations in which reaction rates are controlled by microbiological processes can be described as 
well. Monod terms for electron acceptors and donors can act as catalytic and inhibitory terms in the microbially-mediated rate equations. Mayer et al. (2002) gave a general rate equation for both surface and transport controlled kinetics for mineral dissolution and precipitation. The scripting possibilities in HPx and PHREEQC permit users to incorporate these or alternative rate equations. In addition, rate equations can be defined for sorption processes when implemented as exchange or surface complexation reactions.

\section{Flow-transport-geochemistry interactions}

The concept of scaling hydraulic properties (Vogel et al., 1991), which is typically used in soil sciences to describe their spatial variability, provides a flexible framework for describing the temporal changes of these properties as well. Changes in porosity are then linked to a scaling factor of the water content, $\alpha_{\theta}[-]$, as:

$\alpha_{\theta}(t, x)=\frac{\theta_{\mathrm{s}}(t, x)-\theta_{\mathrm{r}}^{*}}{\theta_{\mathrm{s}}^{*}-\theta_{\mathrm{r}}^{*}}$

where $\theta_{\mathrm{s}}$ is the time- and space-variable saturated water content (or the porosity) $\left[\mathrm{L}^{3} \mathrm{~L}^{-3}\right]$, and $\theta_{\mathrm{S}}^{*}\left[\mathrm{~L}^{3} \mathrm{~L}^{-3}\right]$ and $\theta_{\mathrm{r}}^{*}\left[\mathrm{~L}^{3} \mathrm{~L}^{-3}\right]$ are the reference saturated and residual water contents, respectively, for a specific material. Variations in the hydraulic conductivity in time and space, $K(x, t)\left[\mathrm{L} \mathrm{T}^{-1}\right]$, are described by a scaling factor of the hydraulic conductivity, $a_{\mathrm{K}}[-]$, as follows

$\alpha_{K}(t, x)=\frac{K_{\mathrm{s}}(t, x)}{K_{\mathrm{s}}^{*}}$

where $K_{\mathrm{s}}^{*}$ is the reference saturated hydraulic conductivity for a specific material $\left[\mathrm{L} \mathrm{T}^{-1}\right]$. This formulation enables one to include the effects of temperature and geochemistry on viscosity and density, as well as of precipitation/dissolution/clogging processes on the microstructure. Also, changes in the apparent air-entry value can be described using a scaling factor for the pressure head, $\alpha_{\mathrm{h}}[-]$, such that $h / \alpha_{\mathrm{h}}$ rather than $h$ (for the reference hydraulic properties) is used to obtain the water content and hydraulic conductivity. HPx does not provide any functional relation for calculating the scaling factors. Via the input file, users can implement their preferred model relating geochemical variables to the scaling factors. In the current implementation, change of porosity and scaling factor for the pressure head (in the dual porosity model with water exchange driven by pressure head gradient) are limited to the mobile domain. Assuming a constant porosity of the immobile domain, the change in $\theta_{\mathrm{s}}^{*}$ reflects a change in porosity of the mobile domain only. One limitation is that the scaling factors only describe linear changes in the hydraulic properties. For example, they do not allow for capturing a model for hydraulic property changes which assumes that precipitation and dissolution reactions occur only in the fully water-saturated part of the pore space (e.g., the model of Wissmeier and Barry (2009)). However, when the reactions take place in all of the pore space, the linear scaling model is applicable (Wissmeier and Barry, 2010).

HPx can also update solute and heat transport properties such as the tortuosity of the aqueous and gaseous phases, and the dispersivity, heat capacity, heat conductivity, and heat dispersivity. Tortuosity is often linked to porosity using Archie's law or the model of Millington and Quirk (1961). For cement systems, some models discriminate between the types of porosity (gel versus capillary porosity) and associated cement phases (Patel et al., 2016). The heat capacity can be linked to individual heat capacities of the minerals in the system. However, not much literature evidence exists for a model linking dispersivity and conductivity to geochemical state variables.

\section{Root solute uptake}

Kinetic uptake and exudation processes can be implemented in HPx using rate expressions defined in the input files. Examples of PHREEQC implementations of these types of processes were given by Seuntjens et al. (2004) and Nowack et al. (2006). Compared to the HYDRUS implementations, also available in HPx, some additional features can be taken into account when the rate equations $R_{\mathrm{m}, k}^{\mathrm{kin}}$ in Eq. (4) are used, such as speciesspecific uptake rather than uptake of an element irrespective of the distribution among different aqueous species, inclusion of counter-ions, root exudation, and uptake parameters depending upon soil geochemistry. It is also possible to incorporate the

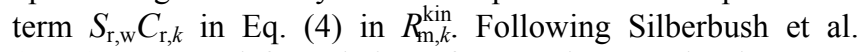
(2005), a general formulation of root solute uptake that combines passive and active uptake is given by

$$
\begin{aligned}
& r_{l}=p_{l}+a_{l} \\
& =p_{l}+A_{\mathrm{root}} J_{l, \max }\left(\omega_{\mathrm{gc}}\right) \frac{c_{l}-c_{l, \mathrm{~min}}}{K_{l, \mathrm{~m}}\left(\omega_{\mathrm{gc}}\right)+\left(c_{l}-c_{l, \min }\right)} \\
& p_{\mathrm{a}, l}=\min \left[S_{\mathrm{w}, \mathrm{r}} \min \left[c_{l}, c_{\mathrm{max}, l}\right],\right. \\
& A_{\mathrm{root}} J_{\mathrm{p}, \max , l}\left(\omega_{\mathrm{gc}}\right), \\
& \left.p_{\mathrm{p}, l}\right] \text { if } c_{l}>c_{\mathrm{r}, l} \\
& =0 \text { otherwise }
\end{aligned}
$$

where $r_{l}$ refers to the uptake of a species $l, p_{l}$ and $a_{l}$ are passive and active uptake rates $\left[\mathrm{mol} / \mathrm{dm}^{3} \mathrm{~T}^{-1}\right], c_{\text {max }, l}$ is the maximum allowed concentration for passive uptake $\left[\mathrm{mol} / \mathrm{dm}^{3}\right], A_{\text {root }}$ is the root surface area $\left[\mathrm{L}^{2} / \mathrm{dm}^{3}\right], J_{\mathrm{p}, \text { max }, l}$ is the maximum allowed passive nutrient uptake rate $\left[\mathrm{mol} \mathrm{L}^{-2} \mathrm{~T}^{-1}\right], \omega$ is the current geochemical condition, $p_{\mathrm{p}, l}$ is the potential passive nutrient uptake rate $\left[\mathrm{mol} / \mathrm{dm}^{3} \mathrm{~T}^{-1}\right], c_{\mathrm{r}, l}$ is the critical concentration below which passive root uptake is zero $\left[\mathrm{mol} / \mathrm{dm}^{3}\right], J_{l, \text { max }}$ is the maximum active nutrient uptake which may depend on geochemical conditions or the maximum potential active uptake $\left[\mathrm{T}^{-1}\right], K_{l, \mathrm{~m}}$ is the Michaelis-Menten parameter $\left[\mathrm{mol} / \mathrm{dm}^{3}\right]$, and $c_{l, \text { min }}$ is the minimum nutrient concentration below which active uptake is zero. The expression for passive uptake is generic as it limits uptake by (i) a maximum allowable concentration for uptake, (ii) a maximum nutrient uptake flux, and (iii) the maximum potential root uptake rate. It is important to note that it is not straightforward to implement active and passive uptake processes as discussed by Šimůnek and Hopmans (2009), in which active uptake is only invoked when passive uptake does not meet a maximum nutrient plant demand.

\section{OVERVIEW OF RECENT APPLICATIONS}

The early studies of Jacques et al. (2008a, 2008b) illustrated the coupled effects of water flow dynamics and geochemistry on the mobility and availability of various contaminants. Since water content variations due to the temporal nature of precipitation, infiltration, and evapotranspiration continually change concentrations in the aqueous phase, other chemical factors and processes such as ionic strength, $\mathrm{pH}$, and aqueous complexation are affected as well. Differences in component mobility result in changes in aqueous speciation and, consequently, both 

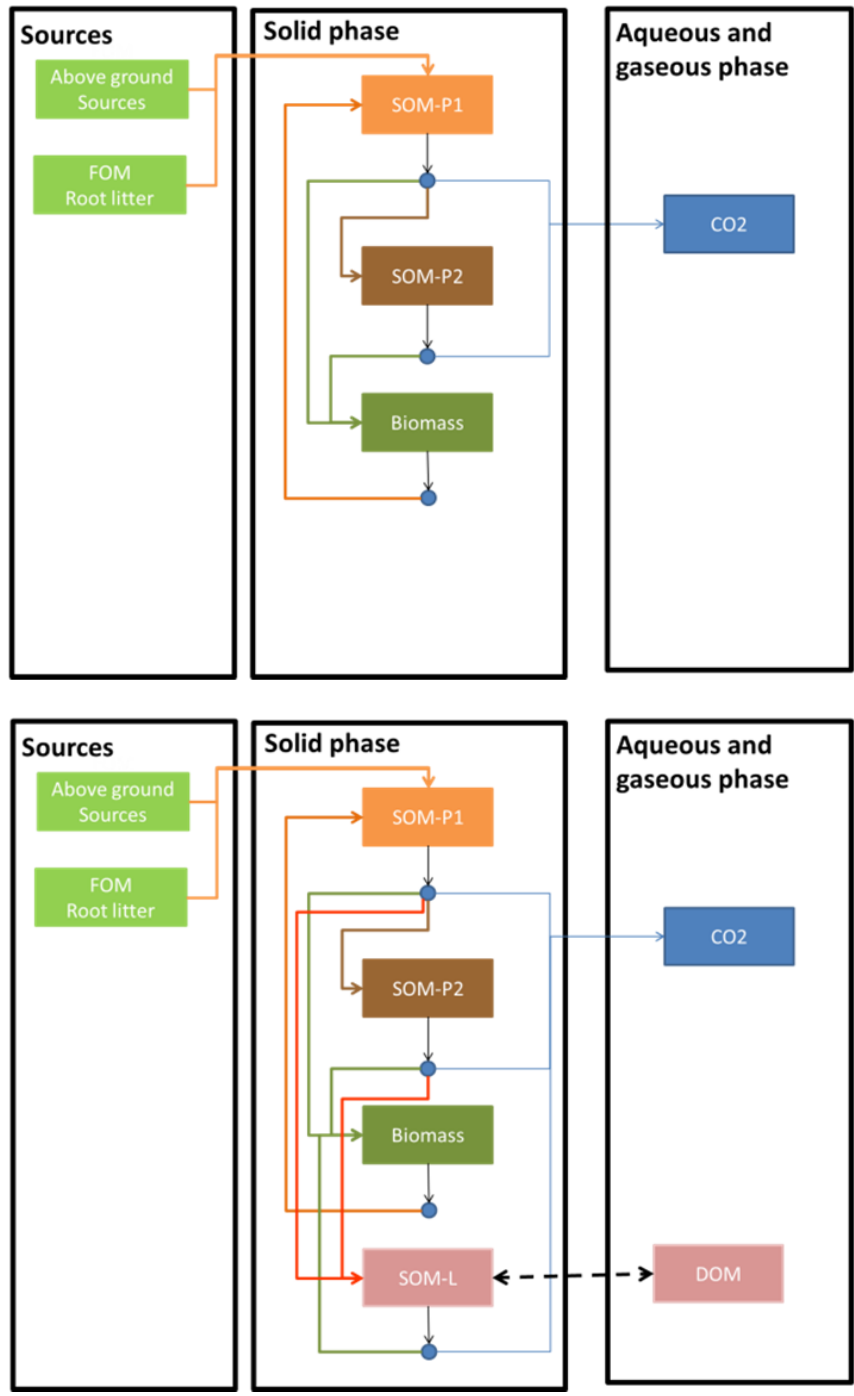

Fig. 4. Organic matter decomposition networks: (top) a scheme without leachable soil organic matter, (bottom) a scheme with leachable soil organic matter. Orange lines indicate decomposition to easily decomposable soil organic matter (SOM-P1), brown lines indicate decomposition to slowly decomposable soil organic matter (SOM-P2), green lines indicate assimilation into biomass (Biomass), blue lines indicate respiration and production of inorganic carbon species $\left(\mathrm{CO}_{2}\right)$, and red lines indicate decomposition towards leachable soil organic matter (SOM-L). The dashed black line represents kinetic exchange between leachable soil organic matter and dissolved organic matter.

mineral dissolution/precipitation and sorption can be affected by the temporal-spatial variability of water contents and water fluxes. Comprehensive studies and/or assessments of fate and transport of contaminants in soil systems need to take into account these types of variations. HPx already has been applied in many studies, including for evaluation of $\mathrm{Hg}$ fate in soil systems (Bessinger and Marks, 2010; Leterme and Jacques, 2015; Leterme et al., 2014) or, more recently, scenario analyses involving the transport of trace metals in a soil leached with coal seam gas produced water (Mallants et al., 2017). The benchmark study of Greskowiak et al. (2015), in which HPx was used as one of several reactive transport models they evaluated, illustrated the applicability of HPx to describe U transport using a multi-rate mass transfer model (MRMT, e.g., Haggerty and Gorelick (1995)).
Another benchmark study was used to verify the implementation of changes in the porosity, diffusion coefficient and hydraulic conductivity as a consequence of mineral precipitation and dissolution in multiple reactive transport models (Xie et al., 2015), including HP1. Valdes-Abellan et al. (2017) developed a model (using HP1) to simulate the spatial-temporal evolution of soil hydraulic properties during non-conventional water irrigation during non-isothermal transient flow. In addition to linking the porosity, $a_{\mathrm{h}}$, and the saturated hydraulic conductivity to the amount of precipitated or dissolved minerals, soil hydraulic properties were also linked to changes in the soil water composition, salinity, and temperature. ValdesAbellan et al. (2017) in their study indicated that a close interplay exist between gypsum-calcite dissolution/precipitation, evaporation fronts, and the key role of the partial pressure of $\mathrm{CO}_{2}$. While the partial pressure of $\mathrm{CO}_{2}$ was linked only to calcite equilibria, the role of organic matter degradation (and corresponding $\mathrm{CO}_{2}$ production) could potentially be incorporated within the HPx framework as well (see below).

HYDRUS in its specialized C-Ride add-on module solves a set of equations describing the transport of colloid and colloidfacilitated solute transport (Šimůnek et al., 2006). A similar set of equations can be implemented in HPx, thus allowing one to consider the effects of geochemistry on various parameters such as attachment efficiency or competitive sorption on the transport of colloids. Zhou et al. (2016) developed a model simulating the transport of three antibiotics in the presence of different kinds of natural organics originating from manure. Compared to the comprehensive capabilities in the standard HYDRUS code, HPx can account for competitive sorption of antibiotics to the soil using a Langmuir competitive kinetic adsorption model in conjunction with competitive kinetic sorption on mobile and immobile organic colloids. The role of geochemistry on colloid mobility was described in a study by Makselon et al. (2017) who modeled the transport of silver nanoparticles in an experiment with flow interruption, evaporation, and ionic strength changes. Ionic strength, and hence the general aqueous geochemical conditions, determined the value of the attachment efficiency, which can be calculated using DVLO theory. A lower ionic strength results in a lower attachment efficiency because of a higher energy barrier and a smaller secondary minimum. BASIC scripts in the input file included root finding algorithms to identify the primary and secondary minima to obtain the attachment efficiency as a function of the changing geochemical conditions during the transport experiment.

\section{EXAMPLES \\ Organic matter dynamics}

As an illustration of the flexible framework of HPx to define reaction networks in general, and for soil organic matter (SOM) degradation in particular, a reaction network loosely based on a study by Porporato et al. (2003) was implemented for this example (HPx projects are available at https://www.pcprogress.com/en/Default.aspx?h1d-library). For convenience, the single-porosity model formulation is used in this example. Figure 4 shows the network with three organic matter pools: (i) a fast decomposable SOM pool (SOM-P1) with concentration $C_{\text {SOM-P1 }}$, (ii) a slow decomposable SOM pool (SOM-P2) with concentration $C_{\mathrm{SOM}-\mathrm{P} 2}$, and (iii) a biomass pool (Biomass) with concentration $C_{\mathrm{B}}$. In addition, inorganic carbon is released in the aqueous and gaseous soil phases during decomposition, $C_{\mathrm{I}}$.

This decomposition is described in terms of four ordinary differential equations: 
$\frac{\mathrm{d} C_{\mathrm{SOM}-\mathrm{P} 1}}{\mathrm{~d} t}=i_{\mathrm{F}}+d_{\mathrm{B}}-d_{\mathrm{SOM}-\mathrm{P} 1}$

$\frac{\mathrm{d} C_{\mathrm{SOM}-\mathrm{P} 2}}{\mathrm{~d} t}=r_{\mathrm{SOM}-\mathrm{P} 1 \rightarrow \mathrm{P} 2} d_{\mathrm{SOM}-\mathrm{P} 1}-d_{\mathrm{SOM}-\mathrm{P} 2}$

$\frac{\mathrm{d} C_{\mathrm{B}}}{\mathrm{d} t}=r_{\text {SOM-P1 } \rightarrow \mathrm{B}} d_{\text {SOM-P1 }}+r_{\text {SOM-P2 } \rightarrow \mathrm{B}} d_{\text {SOM-P2 }}-d_{\mathrm{B}}$

$R_{\mathrm{m}, \mathrm{C}(4)}^{\mathrm{kin}}=r_{\mathrm{SOM}-\mathrm{P} 1 \rightarrow \mathrm{I}} d_{\mathrm{SOM}-\mathrm{P} 1}+r_{\mathrm{SOM}-\mathrm{P} 2 \rightarrow \mathrm{I}} d_{\mathrm{SOM}-\mathrm{P} 2}$

where $d_{X}$ refers to the decomposition rates, $r_{x \rightarrow y}$ denotes the fraction of the decomposition products of pool $x$ going to pool $y$, and $i_{\mathrm{F}}$ denotes the addition of fresh organic matter as litter fall on top of the soil profile or as root decay. Wutzler and Reichstein (2008) discussed different model formulations that can be used to include decomposer biomass into the decomposition rates: (i) no representation of the biomass using equations that are based only on the substrate, (ii) a linear representation of biomass, and (iii) a nonlinear representation of biomass. These models differ in the scaling behavior with the substrate and how they represent priming effects. Although all of these formulations could be included in HPx, the example given below is limited to a non-explicit representation of the biomass and a linear model of the available substrate, i.e.,

$d_{X}=k_{X} C_{X}$

where $k_{X}$ is the first-order decomposition term $\left[\mathrm{T}^{-1}\right], C_{X}$ is the concentration of the substrate $\left[\mathrm{ML}^{-3}\right]$, and $X$ denotes a soil organic matter pool. The value of the rate parameter $k_{X}$ may depend on temperature $f_{\mathrm{T}}(T)[-]$ and soil moisture $f_{\mathrm{M}}\left(S_{\theta}\right)[-]$ as follows:

$k_{X}=k_{X, 0} f_{T}(T) f_{M}\left(S_{\theta}\right)$

where $k_{X, 0}$ is the reference rate $\left[\mathrm{T}^{-1}\right]$. Sierra et al. (2012) gave an overview of different functions to account for the effects of environmental factors on the degradation rate. Here we describe $f_{\mathrm{M}}\left(S_{\theta}\right)$ using the equations of Porporato et al. (2003):

$f_{\mathrm{M}}\left(S_{\theta}\right)= \begin{cases}\frac{S_{\theta}}{S_{\mathrm{fc}}} & S_{\theta} \leq S_{\mathrm{fc}} \\ \frac{S_{\mathrm{fc}}}{S_{\theta}} & S_{\theta}>S_{\mathrm{fc}}\end{cases}$

where $S_{\theta}$ is the degree of saturation $\left(=\theta / \theta_{\mathrm{s}}\right)[-]$ and $S_{\mathrm{fc}}$ is the saturation degree at field capacity $[-]$. The temperature dependency is described using the formulation from ROTC (Jenkinson et al., 1990):

$$
f_{\mathrm{T}}(T)=\frac{47.9}{1+\exp \left(\frac{106}{T+18.3}\right)}
$$

Still needed to complete the description of the organic matter decomposition network is an aqueous speciation model for inorganic $\mathrm{C}$ species. We refer to the Appendix for details. Table 2 further gives the parameters used in a transient flow simulation for a meteorological time series representative of Belgium conditions.
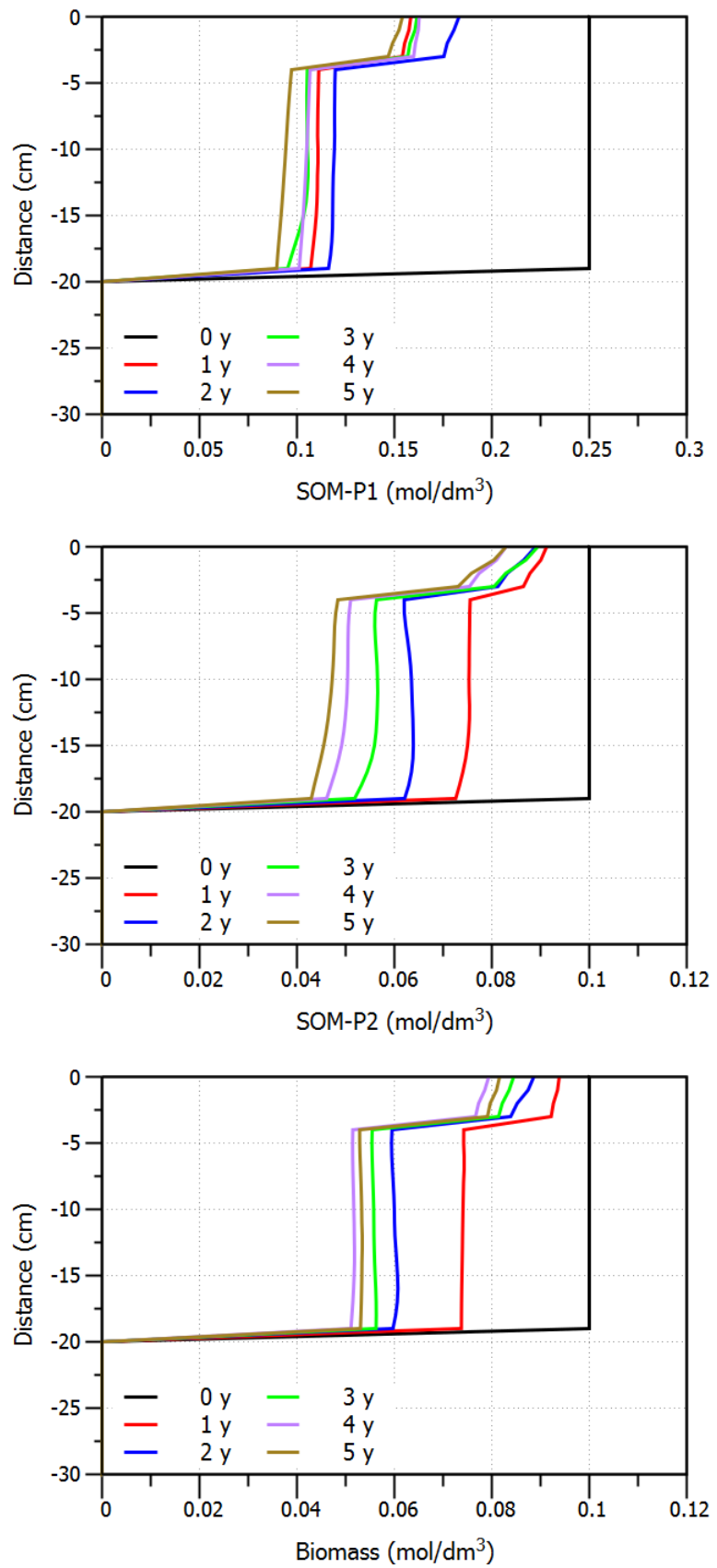

Fig. 5. Profiles of SOM-P1 (top), SOM-P2 (middle), and Biomass (bottom) for network 1.

Figure 5 shows the computed distributions versus depth of the various pools of soil organic matter and biomass during five consecutive years. Large changes during the first few years indicate that selected initial and production terms are not in long-term equilibrium with the degradation processes. The current set of parameters and meteorological variables do not produce much variability in the vertical direction. The relative enrichment of the top $5 \mathrm{~cm}$ is due to SOM-P1 originating both from litter fall and root decay whereas deeper in the profile, only root decay contributes to the SOM-P1 pool. A more throughout analysis of the model setup using a sensitivity analysis of the model parameters is beyond the scope of the current paper but could be done straightforwardly with HPx as was illustrated by Leterme and Jacques (2015). 

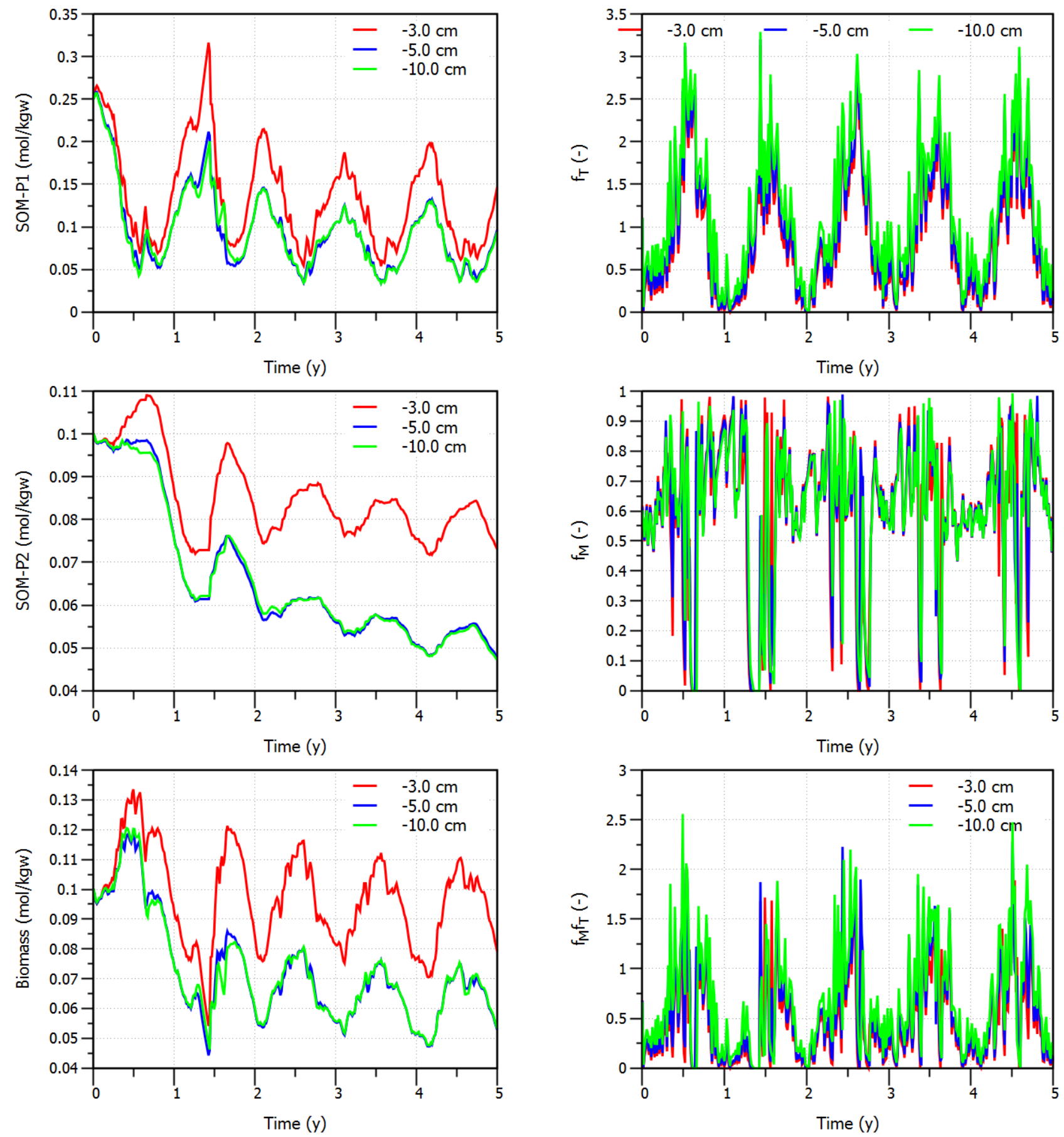

Fig. 6. Time series of SOM-P1 (top), SOM-P2 (middle), and Biomass (bottom) for network 1.

Figure 6 shows time series of various pools of SOM and Biomass at several depths. The strong seasonal fluctuations in these pools are due to variations in soil water contents and temperatures, leading to changes in the environmental factors on the degradation rates as expressed by Eqs. (21)-(23). As shown in Figure 7, variations in $f_{\mathrm{M}}$ and $f_{\mathrm{T}}$ are similar at different soil depths, which explain the relatively uniform distribution of various organic pools (Figure 5). HPx in general provides geochemical information of the system such as $\mathrm{pH}$ (not further shown here) and inorganic aqueous and gaseous $\mathrm{C}$ concentrations, the latter shown in Figure 8 in terms of the partial pressure of $\mathrm{CO}_{2}$ in the soil air phase. In this example $\mathrm{C}$ was the only aqueous species and no $\mathrm{pH}$ controlling

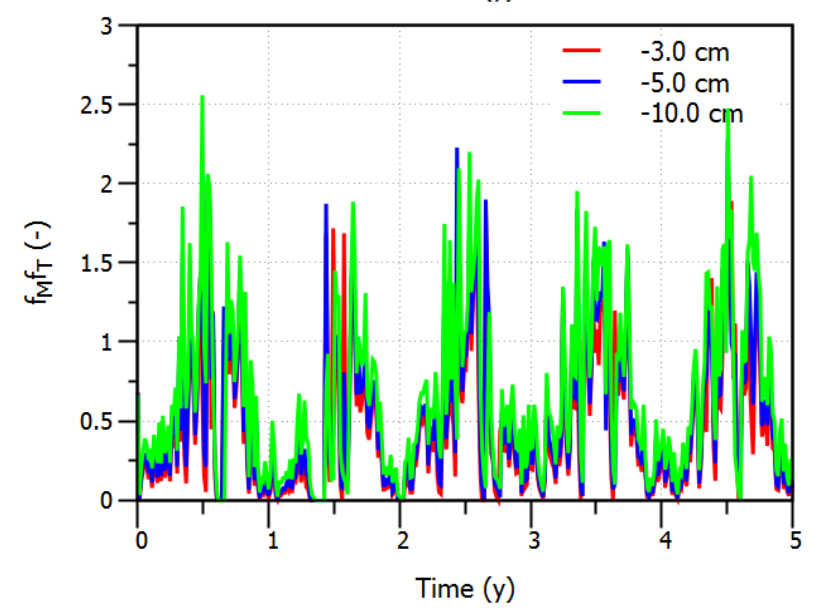

Fig. 7. Time series of $f_{\mathrm{M}}$ (top), $f_{\mathrm{T}}$ (middle), and $f_{\mathrm{M}} f_{\mathrm{T}}$ (bottom) for network 1.

components or processes were included. Figure 8 also shows the cumulative flux of $\mathrm{CO}_{2}$ from the soil to the atmosphere, which is a critical variable in soil-plant-atmosphere and regional or global climate studies (e.g., Thaysen et al. (2014)).

\section{Dissolved organic matter}

The previous organic matter degradation model is further extended in this example by including a leachable organic matter pool (SOM-L) and a dissolved organic matter pool (DOM), which are both kinetically exchanged. The formulation, loosely based on the model of Braakhekke et al. (2011), allows for 

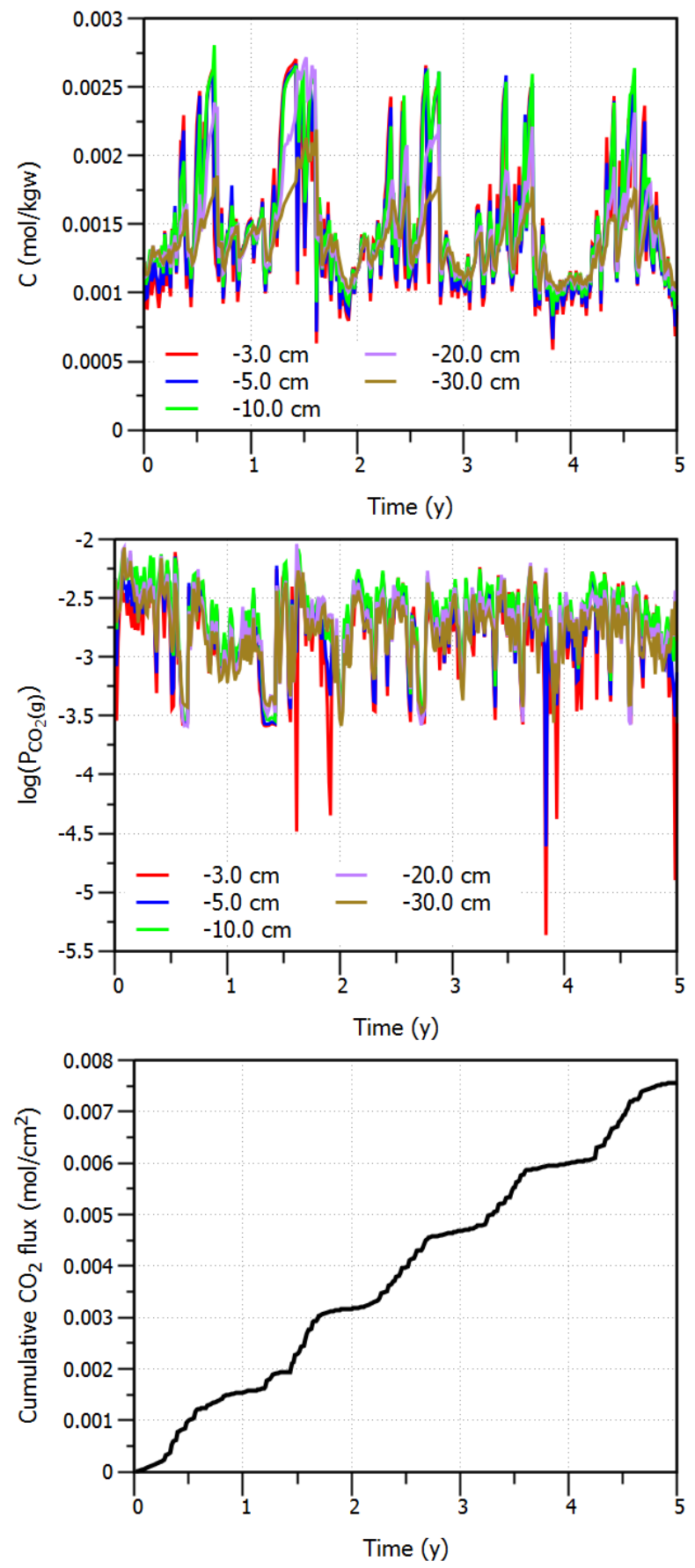

Fig. 8. Time series of $\mathrm{C}$ concentration (mol/kgw) (top), $\mathrm{P}_{\mathrm{CO} 2}$ (middle) and cumulative $\mathrm{CO}_{2}$ flux to the atmosphere (bottom) for network 1 .

advective-dispersive transport of DOM. The set of governing ordinary-differential equations is as follows:

$$
\begin{aligned}
& \frac{\mathrm{d} C_{\text {SOM-P1 }}}{\mathrm{d} t}=i_{\mathrm{F}}+d_{\mathrm{B}}-d_{\text {SOM-P1 }} \\
& \frac{\mathrm{d} C_{\text {SOM-P2 }}}{\mathrm{d} t}=r_{\text {SOM-P1 } \rightarrow \mathrm{P} 2} d_{\text {SOM-P1 }}-d_{\text {SOM-P2 }} \\
& \frac{\mathrm{d} C_{\mathrm{B}}}{\mathrm{d} t}=r_{\text {SOM-P } \rightarrow \mathrm{B}} d_{\text {SOM-P1 }}+r_{\text {SOM-P2 } \rightarrow \mathrm{B}} d_{\text {SOM-P2 }} \\
& +r_{\text {SOM-L } \rightarrow \mathrm{B}} d_{\text {SOM-L }}-d_{\mathrm{B}}
\end{aligned}
$$
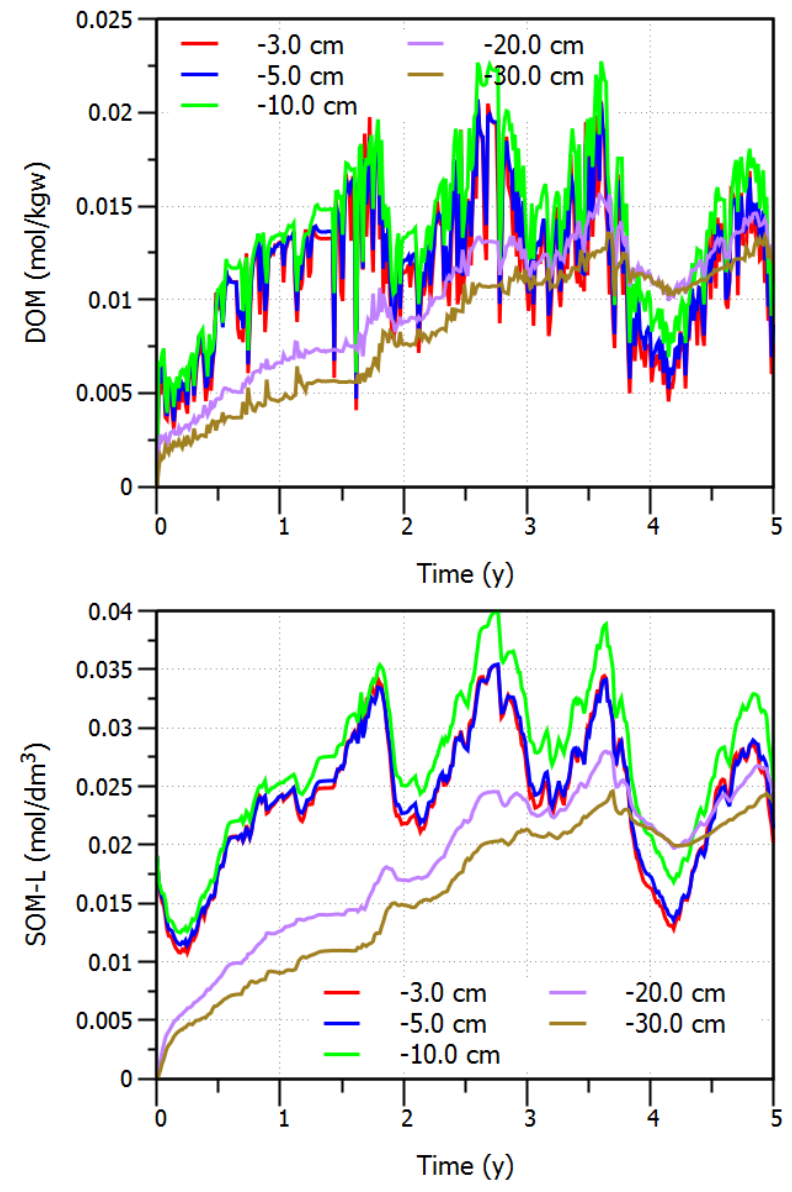

Fig. 9. Time series of DOM (top) and SOM-L (bottom) for network 2.

$$
\begin{aligned}
& \frac{\mathrm{d} C_{\mathrm{SOM}-\mathrm{L}}}{\mathrm{d} t}=r_{\mathrm{SOM}-\mathrm{P} 1 \rightarrow \mathrm{SOM}-\mathrm{L}} d_{\mathrm{SOM}-\mathrm{P} 1}+r_{\mathrm{SOM}-\mathrm{P} 2 \rightarrow \mathrm{SOM}-\mathrm{L}} d_{\mathrm{SOM}-\mathrm{P} 2} \\
& -d_{\mathrm{SOM}-\mathrm{L}}-d_{\mathrm{S}} \\
& R_{\mathrm{m}, \mathrm{C}(4)}^{\mathrm{kin}}=r_{\mathrm{SOM}-\mathrm{P} 1 \rightarrow \mathrm{I}} d_{\text {SOM-P1 }}+r_{\mathrm{SOM}-\mathrm{P} 2 \rightarrow \mathrm{I}} d_{\mathrm{SOM}-\mathrm{P} 2}+r_{\mathrm{SOM}-\mathrm{L} \rightarrow \mathrm{I}} d_{\mathrm{SOM}-\mathrm{L}} \\
& R_{\mathrm{m}, \mathrm{DOM}}^{\mathrm{kin}}=d_{\mathrm{s}}
\end{aligned}
$$

where $d_{\mathrm{S}}$ is the desorption term:

$$
\begin{aligned}
d_{\mathrm{S}} & =k_{\mathrm{S}}\left(C_{\mathrm{SOM}-\mathrm{L}}-C_{\mathrm{SOM}-\mathrm{L}}^{\mathrm{eq}}\right) \\
& =k_{\mathrm{S}}\left(C_{\mathrm{SOM}-\mathrm{L}}-\frac{K_{\mathrm{L}} S_{\mathrm{max}} C_{\mathrm{DOM}}}{1+K_{\mathrm{L}} C_{\mathrm{DOM}}}\right)
\end{aligned}
$$

in which $K_{\mathrm{L}}$ is the coefficient of binding affinity $\left[\mathrm{dm}^{3} \mathrm{gC}^{-1}\right]$ and $S_{\max }$ the maximum adsorption capacity $\left[\mathrm{gC} \mathrm{dm}^{-3}\right.$. Time series of the new two pools, SOM-L and DOM, are shown in Figure 9. DOM shows short-scale temporal variations due to changes in the water content. These variations are less pronounced for SOM-L due to the kinetics of the sorption process. The advection and dispersion of DOM result in an increase in both DOM and SOM-L at depths below the initial source of soil organic matter between 0 and $20 \mathrm{~cm}$ below the soil surface. Note that the other pools potentially will develop also below the $20-\mathrm{cm}$ depth when this degradation scheme is used, but their amounts remain very small for the chosen set of parameters. 

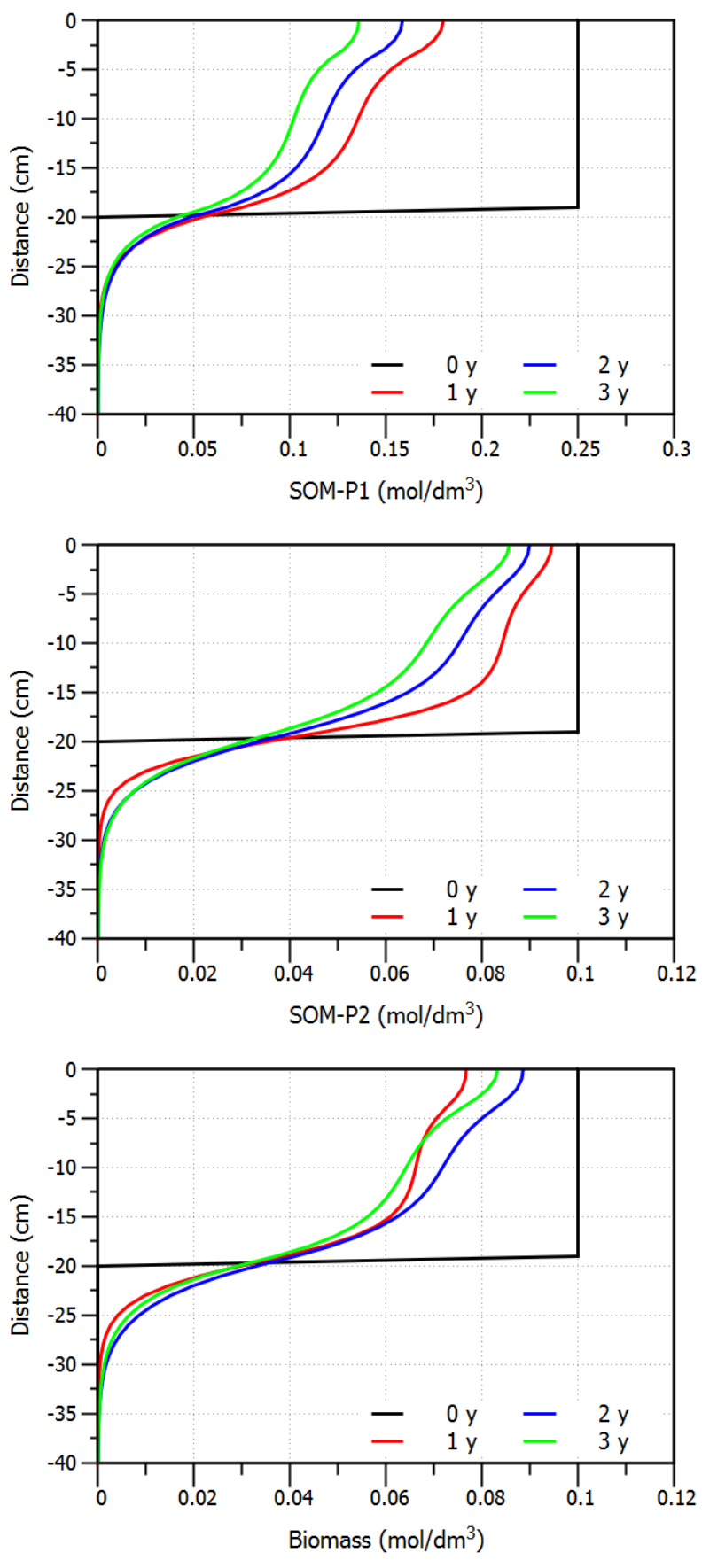

Fig. 10. Profiles of SOM-S1 (top), SOM-S2 (middle) and Biomass (bottom) for a simulation with network 1 including biodiffusion.

\section{Bioturbation}

The long term prediction of soil carbon cycling requires an explicit representation of the vertical distribution of soil organic matter, and hence a model able to represent processes leading to the vertical distribution of SOM such as the root litter distribution and the transport of soil organic matter (Braakhekke et al., 2011). The biological transport of soil solid phases, often referred to as bioturbation, depends strongly on the behavior of the biological community species, which necessitated the development of different modeling approaches (Meysman et al., 2003a). Models based on Fick's law are local random models (Meysman et al., 2005), whereas non-local models need to be employed when ingestion and egestion processes of SOM by bio fauna are vertically separated (Jarvis et al., 2010).
As an example, a biodiffusion model was implemented within the input files of HPx:

$J_{\mathrm{s}, X}=-D_{\mathrm{B}, X} \frac{\partial C_{X}}{\partial x}$

where $J_{\mathrm{s}, X}$ is the solid phase diffusive flux of the $X$ th pool [mol $\left.\mathrm{T}^{-1} \mathrm{~L}^{-2}\right], D_{\mathrm{B}, X}$ is the effective solid phase diffusion coefficient $\left[\mathrm{L}^{2} \mathrm{~T}^{-1}\right]$, and $C_{X}$ is the solid phase concentration $\left[\mathrm{mol} \mathrm{L}^{-3}\right]$. The biodiffusion model was applied to organic network 1 described above with SOM-P1, SOM-P2, and biomass. We assumed rather arbitrarily that $D_{\mathrm{B}, X}=10^{-10} \mathrm{~m}^{2} / \mathrm{s}$. As shown in Figure 10, a smooth profile of the three organic pools developed over the course of 3 years to about $15 \mathrm{~cm}$ below the initial layer with organic matter.

\section{CONCLUSIONS}

The original HP1 model (Jacques and Šimůnek, 2005; Jacques et al., 2006) has seen many extensions during the past 10 years or more. The most important changes were the development of two- and three-dimensional versions (HPx), and the incorporation of the software PHREEQC-3, OpenMP, enhanced scripting possibilities, diffusion in the gas phase of reactive gases in the software, and linking geochemical state variables to transport properties. Using the terminology of Meysman et al. (2003b), HPx is now moving towards a more flexible and extendible problem-solving environment to allow users to incorporate a range of user-defined conceptual models to tackle their specific projects. Flexibility and extendibility are discussed in this manuscript with respect to coupling geochemistry with transport properties, colloid and colloid-affected transport, bioturbation, and root solute uptake. Recent applications show that HPx, and similar reactive transport codes, are useful tools to evaluate many environmental and engineering problems both from a scientific as well as from an application point of view, thus underpinning the main statement from Li et al. (2017).

In this paper, we illustrated the capabilities and flexibility of HPx by developing a reaction-transport model for soil organic matter, in which we included different factors important in soil organic matter degradation. Only a few SOM degradation models can similarly consider spatial-temporal variations in water contents, water fluxes, and temperatures, as well as different conceptual models for SOM degradation networks, advectiondispersive transport of DOM, $\mathrm{CO}_{2}$ transport, and bioturbation in one modeling framework. Within the scope of this paper, the role of microbial processes together with the transport of oxygen were not addressed, but conceptually could be implemented in a very similar way. We also acknowledge that further parameter sensitivity studies and validation of these models are crucial in further model applications.

Acknowledgement. The first author acknowledges the support of the Belgian Nuclear Research Centre for developing, maintaining, and applying the HPx code.

\section{REFERENCES}

Aagaard, P., Helgeson, H.C., 1982. Thermodynamic and kinetic constraints on reaction rates among minerals and aqueous solutions, 1. Theoretical considerations. Am. J. Sci., 282, 237-285.

Amos, R.T., Mayer, K.U., 2006. Investigating the role of gas bubble formation and entrapment in contaminated aquifers: Reactive transport modelling. J. Cont. Hydrol., 87, 123-154. 
Appelo, C.A.J., Parkhurst, D.L., Post, V.E.A., 2014. Equations for calculating hydrogeochemical reactions of minerals and gases such as $\mathrm{CO}_{2}$ at high pressures and temperatures. Geochim. Cosmochim. Acta, 125, 49-67.

Appelo, C.A.J., Wersin, P., 2007. Multicomponent diffusion modeling in clay systems with application to the diffusion of tritium, iodide, and sodium in Opalinus Clay. Env. Sci. Tech., 41, 5002-5007.

Batlle-Aguilar, J., Brovelli, A., Porporato, A., Barry, D.A., 2011. Modelling soil carbon and nitrogen cycles during land use change: A review. Agron. Sust. Devel., 31, 251-274.

Bennacer, L., Ahfir, N.D., Alem, A., Wang, H.Q., 2017. Coupled effects of ionic strength, particle size, and flow velocity on transport and deposition of suspended particles in saturated porous media. Transp. Por. Med., 118, 251-269.

Bessinger, B.A., Marks, C.D., 2010. Treatment of mercurycontaminated soils with activated carbon: A laboratory, field, and modeling study. Remed., 21, 115-135.

Bloom, S.A., Mansell, R.S., 2001. An algorithm for generating cation exchange isotherms from binary selectivity coefficients. Soil Sci. Soc. Am. J., 65, 1426-1429.

Bond, W.J., 1995. On the Rothmund-Kornfeld description of cation exchange. Soil Sc. Soc. Am. J., 59, 436-443.

Borkovec, M., Westall, J., 1983. Solution of the PoissonBoltzmann equation for surface excesses of ions in the diffuse layer at the oxide electrolyte interface. J. Elect. Chem., 150, 325-337.

Bozorg, A., Gates, I.D., Sen, A., 2015a. Impact of biofilm on bacterial transport and deposition in porous media. J. Cont. Hydrol., 183, 109-120.

Bozorg, A., Gates, I.D., Sen, A., 2015b. Using bacterial bioluminescence to evaluate the impact of biofilm on porous media hydraulic properties. J. Microb. Meth., 109, 84-92.

Braakhekke, M.C., Beer, C., Hoosbeek, M.R., Reichstein, M., Kruijt, B., Schrumpf, M., Kabat, P., 2011. SOMPROF: A vertically explicit soil organic matter model. Ecol. Mod., 222, 1712-1730.

Brantley, S., Goldhaber, M.B., Ragnarsdottir, K.V., 2007. Crossing disciplines and scales to understand the critical zone. Elements, 3, 307-314.

Brooks, R.H., Corey, A., 1964. Hydraulic properties of porous media. Hydrol. Paper No. 3, Colorado State Univ., Fort Collins, CO.

Carles Brangarí, A., Sanchez-Vila, X., Freixa, A., M. Romaní, A., Rubol, S., Fernàndez-Garcia, D., 2017. A mechanistic model (BCC-PSSICO) to predict changes in the hydraulic properties for bio-amended variably saturated soils. Water Resour. Res., 53, 93-109.

Charlton, S.R., Parkhurst, D.L., 2011. Modules based on the geochemical model PHREEQC for use in scripting and programming languages. Comp. \& Geosc., 37, 1653-1663.

Durner, W., 1994. Hydraulic conductivity estimation for soils with heterogeneous pore structure. Water Resour. Res., 30, 211-223.

Dzombak, D.A., Morel, F.M.M., 1990. Surface Complexation Modeling - Hydrous Ferric Oxide. John Wiley, New York.

Freedman, V.L., Bacon, D.H., Saripalli, K.P., Meyer, P.D., 2004. A film depositional model of permeability for mineral reactions in unsaturated media. Vadose Zone J., 3, 14141424.

Greskowiak, J., Gwo, J., Jacques, D., Yin, J., Mayer, K.U., 2015. A benchmark for multi-rate surface complexation and 1D dual-domain multi-component reactive transport of U(VI). Comp. Geosc., 19, 585-597.
Guggenheim, E.A., 1937. Theoretical basis of Raoult's law. Trans. Faraday Soc., 33, 151-159.

Haggerty, R., Gorelick, S.M., 1995. Multiple-rate mass transfer for modeling diffusion and surface reactions in media with pore-scale heterogeneity. Water Resour. Res., 31, 23832400.

Hiemstra, T., VanRiemsdijk, W.H., 1996. A surface structural approach to ion adsorption: The charge distribution (CD) model. J. Col. Int. Sci., 179, 488-508.

Hommel, J., Lauchnor, E., Phillips, A., Gerlach, R., Cunningham, A.B., Helmig, R., Ebigbo, A., Class, H., 2015. A revised model for microbially induced calcite precipitation: Improvements and new insights based on recent experiments. Water Resour. Res., 51, 3695-3715.

Jacques, D., 2009. Benchmarking of the cement model and detrimental chemical reactions including temperature dependent parameters. Project near surface disposal of category A waste at Dessel, NIRAS-MP5-03 DATA-LT(NF) Version 1.

Jacques, D., Šimůnek, J., 2005. User Manual of the Multicomponent Variably- Saturated Flow and Transport Model HP1. SCK •CEN-BLG-998.

Jacques, D., Šimůnek, J., Mallants, D., van Genuchten, M.T., 2006. Operator-splitting errors in coupled reactive transport codes for transient variably saturated flow and contaminant transport in layered soil profiles. J. Contam. Hydrol., 88, 197-218.

Jacques, D., Šimůnek, J., Mallants, D., van Genuchten, M.T., 2008a. Modeling coupled hydrologic and chemical processes: Long-term uranium transport following phosphorus fertilization. Vadose Zone J., 7, 698-711.

Jacques, D., Šimůnek, J., Mallants, D., van Genuchten, M.T., 2008b. Modelling coupled water flow, solute transport and geochemical reactions affecting heavy metal migration in a podzol soil. Geoderma, 145, 449-461.

Jacques, D., Smith, C., Simůnek, J., Smiles, D., 2012. Inverse optimization of hydraulic, solute transport, and cation exchange parameters using HP1 and UCODE to simulate cation exchange. J. Contam. Hydrol., 142-143, 109-125.

Jarvis, N.J., Taylor, A., Larsbo, M., Etana, A., Rosen, K., 2010. Modelling the effects of bioturbation on the re-distribution of ${ }^{137} \mathrm{Cs}$ in an undisturbed grassland soil. Eur. J. Soil Sci., $61,24-34$.

Jenkinson, D.S., Andrew, S.P.S., Lynch, J.M., Goss, J.M., Tinker, P.B., 1990. The turnover of organic carbon and nitrogen in soil. Philosoph. Trans., 329, 361-368.

Kosugi, K., 1996. Lognormal distribution model for unsaturated soil hydraulic properties. Water Resour. Res., $32,2697-2703$.

Laliberté, M., 2007. Model for calculating the viscosity of aqueous solutions. J. Chem. Eng. Data, 52, 321-335.

Laliberté, M., Cooper, W.E., 2004. Model for calculating the density of aqueous electrolyte solutions. J. Chem. Eng. Data, 49, 1141-1151.

Leterme, B., Blanc, P., Jacques, D., 2014. A reactive transport model for mercury fate in soil-application to different anthropogenic pollution sources. Environ. Sci. Pollut. Res., 12279-12293.

Leterme, B., Jacques, D., 2015. A reactive transport model for mercury fate in contaminated soil-sensitivity analysis. Environ. Sci. Pollut. Res., 22, 16830-16842.

Li, L., Maher, K., Navarre-Sitchler, A., Druhan, J., Meile, C., Lawrence, C., Moore, J., Perdrial, J., Sullivan, P., Thompson, A., Jin, L., Bolton, E.W., Brantley, S.L., Dietrich, W.E., Mayer, K.U., Steefel, C.I., Valocchi, A., 
Zachara, J., Kocar, B., McIntosh, J., Tutolo, B.M., Kumar, M., Sonnenthal, E., Bao, C., Beisman, J., 2017. Expanding the role of reactive transport models in critical zone processes. Earth Sci. Rev., 165, 280-301.

Liu, S., Jacques, D., Govaerts, J., Wang, L., 2014. Conceptual model analysis of interaction at a concrete-Boom Clay interface. Phys. Chem. Earth, 70-71, 150-159.

Maes, N., Wang, L., Hicks, T., Bennett, D., Warwick, P., Hall, T., Walker, G., Dierckx, A., 2006. The role of natural organic matter in the migration behaviour of americium in the Boom Clay - Part I: Migration experiments. Phys. Chem. Earth, 31, 541-547.

Makselon, J., Zhou, D., Engelhardt, I., Jacques, D., Klumpp, E., 2017. Experimental and numerical investigations of silver nanoparticle transport under variable flow and ionic strength in soil. Envir. Sci. Techn., 51, 2096-2104.

Mallants, D., Šimůnek, J., van Genuchten, M.T., Jacques, D., 2017. Simulating the fate and transport of coal seam gas chemicals in variably-saturated soils using HYDRUS. Water, 9, 6, 385.

Manzoni, S., Porporato, A., 2009. Soil carbon and nitrogen mineralization: Theory and models across scales. Soil Biol. Biochem., 41, 1355-1379.

Martinez, B.C., DeJong, J.T., Ginn, T.R., 2014. Biogeochemical reactive transport modeling of microbial induced calcite precipitation to predict the treatment of sand in one-dimensional flow. Comp. Geotech., 58, 1-13.

Mayer, K.U., Alt-Epping, P., Jacques, D., Arora, B., Steefel, C.I., 2015. Benchmark problems for reactive transport modeling of the generation and attenuation of acid rock drainage. Comp. Geosci., 19, 599-611.

Mayer, K.U., Frind, E.O., Blowes, D.W., 2002. Multicomponent reactive transport modeling in variably saturated porous media using a generalized formulation for kinetically controlled reactions. Water Resour. Res., 38, 1174, DOI: $1110.1029 / 2001$ WR000862.

Mays, D.C., Hunt, J.R., 2007. Hydrodynamic and chemical factors in clogging by montmorillonite in porous media. Envir. Sci. Techn., 41, 5666-5671.

Meysman, F.J.R., Boudreau, B.P., Middelburg, J.J., 2003 a. Relations between local, nonlocal, discrete and continuous models of bioturbation. J. Mar. Res., 61, 391-410.

Meysman, F.J.R., Boudreau, B.P., Middelburg, J.J., 2005. Modeling reactive transport in sediments subject to bioturbation and compaction. Geochim. Cosmochim. Acta, 69, 3601-3617.

Meysman, F.J.R., Middelburg, J.J., Herman, P.M.J., Heip, C.H.R., 2003b. Reactive transport in surface sediments. I. Model complexity and software quality. Comp. Geosci., 29, 291-300.

Millington, R.J., Quirk, J.P., 1961. Permeability of porous solids. Trans. Faraday Soc., 57, 1200-1206.

Nowack, B., Mayer, K.U., Oswald, S.E., van Beinum, W., Appelo, C.A.J., Jacques, D., Seuntjens, P., Gérard, F., Jaillard, B., Schnepf, A., Roose, T., 2006. Verification and intercomparison of reactive transport codes to describe rootuptake. Plant and Soil, 285, 305-321.

Or, D., Smets, B.F., Wraith, J.M., Dechesne, A., Friedman, S.P., 2007. Physical constraints affecting bacterial habitats and activity in unsaturated porous media - a review. Adv. Wat. Res., 30, 1505-1527.

Paradelo, M., Perez-Rodriguez, P., Fernandez-Calvino, D., Arias-Estevez, M., Lopez-Periago, J.E., 2012. Coupled transport of humic acids and copper through saturated porous media. Eur. J. Soil Sci., 63, 708-716.
Parkhurst, D.L., Appelo, C.A.J., 2013. Description of Input and Examples for PHREEQC Version 3 - A Computer Program for Speciation, Batch-Reaction, One-Dimensional Transport, and Inverse Geochemical Calculations. Chapter 43 of Section A. Groundwater Book 6, Modeling Techniques.

Parkhurst, D.L., Wissmeier, L., 2015. PhreeqcRM: A reaction module for transport simulators based on the geochemical model PHREEQC. Adv. Wat. Res., 83, 176-189.

Patel, R., Phung, Q.T., Seetharam, S.C., Perko, J., Jacques, D., Maes, N., De Schutter, G., Ye, G., van Breugel, K., 2016. Diffusivity of saturated ordinary Portland cement- based materials: A critical review of experimental and analytical modelling approaches. Cem. Con. Res., 90, 52-72.

Peng, D.-Y., Robinson, D.B., 1976. A new two-constant equation of state. Ind. Eng. Chem. Fund., 15, 59-64.

Phung, Q.T., Maes, N., Jacques, D., De Schutter, G., Ye, G., Perko, J., 2016. Modelling the carbonation of cement pastes under a $\mathrm{CO} 2$ pressure gradient considering both diffusive and convective transport. Const. Build. Mat., 114, 333-351.

Porporato, A., D'Odorico, P., Laio, F., Rodriguez-Iturbe, I., 2003. Hydrologic controls on soil carbon and nitrogen cycles. I. Modeling scheme. Adv. Wat. Res., 26, 45-58.

Puigdomènech, I., Rard, J.A., Plyasunov, A.V., Grenthe, I., 1997. Temperature corrections to thermodynamic data and enthalpy calculations. In: Grenthe, I., PuigdomSnech, I. (Eds.): OECD Nuclear Chemistry, Paris, pp. 427-493.

Riley, W.J., Maggi, F., Kleber, M., Torn, M.S., Tang, J.Y., Dwivedi, D., Guerry, N., 2014. Long residence times of rapidly decomposable soil organic matter: application of a multi-phase, multi-component, and vertically resolved model (BAMS1) to soil carbon dynamics. Geosci. Model Dev., 7, 1335-1355.

Rockhold, M.L., Yarwood, R.R., Niemat, M.R., Bottomley, P.J., Selker, J.S., 2002. Considerations for modeling bacterial-induced changes in hydraulic properties of variably saturated porous media. Adv. Wat. Res., 25, 477-495.

Schmidt, M.W.I., Torn, M.S., Abiven, S., Dittmar, T., Guggenberger, G., Janssens, I.A., Kleber, M., KogelKnabner, I., Lehmann, J., Manning, D.A.C., Nannipieri, P., Rasse, D.P., Weiner, S., Trumbore, S.E., 2011. Persistence of soil organic matter as an ecosystem property. Nature, 478 , 49-56.

Seuntjens, P., Nowack, B., Schulin, R., 2004. Root-zone modeling of heavy metal uptake and leaching in the presence of organic ligands. Plant and Soil, 265, 61-73.

Sharqawy, M.H., Lienhard V, J.H., Zubair, S.M., 2010. Thermophysical properties of seawater: A review of existing correlations and data. Desal. Wat. Treat., 16, 354-380.

Sierra, C.A., Müller, M., Trumbore, S.E., 2012. Models of soil organic matter decomposition: the SoilR package, version 1.0. Geosci. Model Dev., 5, 1045-1060.

Silberbush, M., Ben-Asher, J., Ephrath, J.E., 2005. A model for nutrient and water flow and their uptake by plants grown in a soilless culture. Plant and Soil, 271, 309-319.

Šimůnek, J., He, C., Pang, L., Bradford, S.A., 2006. Colloidfacilitated solute transport in variably saturated porous media: Numerical model and experimental verification. Vadose Zone J., 5, 1035-1047.

Šimůnek, J., Hopmans, J.W., 2009. Modeling compensated root water and nutrient uptake. Ecol. Mod., 220, 505-521.

Šimůnek, J., Jacques, D., Šejna, M., van Genuchten, M.T., 2012. The HP2 Program for HYDRUS (2D/3D). A Coupled Code for Simulating Two-Dimensional Variably-Saturated Water Flow, Head Transport, Solute Transport Flow, and 
Biogeochemistry in Porous Media. (HYDRUS+PHREEQC+2D), Version 1.

Simunek, J., Sejna, M., Saito, H., Sakai, K., van Genuchten, M.T., 2013. The HYDRUS-1D Software Package for Simulating the Movement of Water, Heat, and Multiple Solutes in Variably Saturated Media. Version 4.17. HYDRUS Software Series 3. Department of Environmental Sciences, University of California Riverside, Riverside, California, USA.

Šimůnek, J., van Genuchten, M.T., 2008. Modeling nonequilibrium flow and transport processes using HYDRUS. Vadose Zone J., 7, 782-797.

Šimůnek, J., van Genuchten, M.T., Šejna, M., 2016. Recent developments and applications of the HYDRUS Computer Software Packages. Vadose Zone J., 15, DOI: 10.2136/vzj2016.04.0033.

Steefel, C.I., Appelo, C.A.J., Arora, B., Jacques, D., Kalbacher, T., Kolditz, O., Lagneau, V., Lichtner, P.C., Mayer, K.U., Meeussen, J.C.L., Molins, S., Moulton, D., Shao, H., Šimůnek, J., Spycher, N., Yabusaki, S.B., Yeh, G.T., 2015. Reactive transport codes for subsurface environmental simulation. Comp. Geosci., 19, 445-478.

Steefel, C.I., DePaolo, D.J., Lichtner, P.C., 2005. Reactive transport modeling: An essential tool and a new research approach for the Earth sciences. Earth Plan. Sci. Let., 240, 539-558.

Tang, J., Riley, W.J., 2015. Weaker soil carbon-climate feedbacks resulting from microbial and abiotic interactions. Nature Clim. Change, 5, 56-60.

Tang, J.Y., Riley, W.J., Koven, C.D., Subin, Z.M., 2013. CLM4-BeTR, a generic biogeochemical transport and reaction module for CLM4: model development, evaluation, and application. Geosci. Model Dev., 6, 127-140.

Thaysen, E.M., Jacques, D., Jessen, S., Andersen, C.E., Laloy, E., Ambus, P., Postma, D. and Jakobsen, I., 2014. Inorganic carbon fluxes across the vadose zone of planted andunplanted soil mesocosms. Biogeosci., 11, 7179-7192.

Todd-Brown, K.E.O., Randerson, J.T., Post, W.M., Hoffman, F.M., Tarnocai, C., Schuur, E.A.G., Allison, S.D., 2013. Causes of variation in soil carbon simulations from CMIP5 Earth system models and comparison with observations. Biogeosci., 10, 1717-1736.

Valdes-Abellan, J., Jiménez-Martínez, J., Candela, L., Jacques, D., Kohfahl, C., Tamoh, K., 2017. Reactive transport modelling to infer changes in soil hydraulic properties induced by non-conventional water irrigation. J. Hydrol., $549,114-124$.

van Genuchten, M.T., 1980. Closed-form equation for predicting the hydraulic conductivity of unsaturated soils. Soil Sci. Soc. Am. J., 44, 892-898.

Vereecken, H., Schnepf, A., Hopmans, J.W., Javaux, M., Or, D., Roose, T., Vanderborght, J., Young, M.H., Amelung, W., Aitkenhead, M., Allison, S.D., Assouline, S., Baveye, P., Berli, M., Brüggemann, N., Finke, P., Flury, M., Gaiser, T., Govers, G., Ghezzehei, T., Hallett, P., Hendricks Franssen, H.J., Heppell, J., Horn, R., Huisman, J.A., Jacques, D., Jonard, F., Kollet, S., Lafolie, F., Lamorski, K., Leitner, D., McBratney, A., Minasny, B., Montzka, C., Nowak, W., Pachepsky, Y., Padarian, J., Romano, N., Roth, K., Rothfuss, Y., Rowe, E.C., Schwen, A., Šimůnek, J., Tiktak, A., Van Dam, J., van der Zee, S.E.A.T.M., Vogel, H.J., Vrugt, J.A., Wöhling, T., Young, I.M., 2016. Modeling soil processes: Review, key challenges, and new perspectives. Vadose Zone J., 15, 1-57.
Vogel, T., Cislerova, M., Hopmans, J.W., 1991. Porous media with linearly variable hydraulic properties. Water Resour. Res., 27, 2735-2741.

Wissmeier, L., Barry, D.A., 2009. Effect of mineral reactions on the hydraulic properties of unsaturated soils: Model development and application. Adv. Wat. Res., 32, 12411254.

Wissmeier, L., Barry, D.A., 2010. Implementation of variably saturated flow into PHREEQC for the simulation of biogeochemical reactions in the vadose zone. Env. Mod. Soft., 25, 526-538.

Wutzler, T., Reichstein, M., 2008. Colimitation of decomposition by substrate and decomposers - a comparison of model formulations. Biogeosci., 5, 749-759.

Xie, M., Mayer, K.U., Claret, F., Alt-Epping, P., Jacques, D., Steefel, C., Chiaberge, C., Šimůnek, J., 2015. Implementation and evaluation of permeability-porosity and tortuosity-porosity relationships linked to mineral dissolution-precipitation. Comp. Geosci., 19, 655-671.

Yarwood, R.R., Rockhold, M.L., Niemet, M.R., Selker, J.S., Bottomley, P.J., 2006. Impact of microbial growth on water flow and solute transport in unsaturated porous media. Water Resour. Res., 42, W10405, 1-11.

Yu, C., Muñoz-Carpena, R., Gao, B., Perez-Ovilla, O., 2013. Effects of ionic strength, particle size, flow rate, and vegetation type on colloid transport through a dense vegetation saturated soil system: Experiments and modeling. J. Hydrol., 499, 316-323.

Zhou, D., Thiele-Bruhn, S., Arenz-Leufen, M.G., Jacques, D., Lichtner, P., Engelhardt, I., 2016. Impact of manure-related DOM on sulfonamide transport in arable soils. J. Contam. Hydrol., 192, 118-128.

Received 12 July 2017 Accepted 21 September 2017

\section{APPENDIX - Details about the organic matter degradation model.}

The aquatic geochemical reactions within the adopted modeling approach are limited to the inorganic carbon reactions, as given in Table 1. For all aqueous species, the activity correction model of WATEQ is used:

$$
\log \gamma=\frac{-A z^{2} \sqrt{\mu}}{1+B a \sqrt{\mu}}+b \mu
$$

where $\gamma$ is the activity correction coefficient, $z$ is the charge, $\mu$ is the ionic strength, $A$ and $B$ are constants at a given temperature, and $a$ and $b$ are species-dependent parameters, except for $\mathrm{CO}_{2}$ for which the activity coefficient is obtained as $\log \gamma=0.1$ $\mu$. The temperature dependence of the mass action constant is given as:

$\log _{10} K=A_{1}+A_{2} T+\frac{A_{3}}{T}+A_{4} \log _{10} T+\frac{A_{5}}{T^{2}}+A_{6} T^{2}$

where $A_{1}, \ldots, A_{6}$ are parameters and $T$ is temperature in Kelvin. The relevant temperature range is limited between $\sim 0$ to $\sim 30^{\circ} \mathrm{C}$.

Tables 2 through 5 provide a list of parameter definitions and values used in the simulations of the organic matter degradation networks. 
Table 1. Overview of species, geochemical reactions, and thermodynamic parameters (values are from the phreeqc.dat database as incorporated in PHREEQC-3).

\begin{tabular}{|c|c|c|c|c|c|c|c|c|c|}
\hline \multirow[t]{2}{*}{ Species } & \multirow[t]{2}{*}{ Reaction } & \multicolumn{2}{|c|}{ Activity correction } & \multicolumn{6}{|c|}{ Temperature dependence } \\
\hline & & $a$ & $b$ & $A_{1}$ & $A_{2}$ & $A_{3}$ & $A_{4}$ & $A_{5}$ & $A_{6}$ \\
\hline $\mathrm{H}^{+}$ & & 9.0 & 0 & & & & & & \\
\hline $\mathrm{CO}_{3}^{2-}$ & & 5.4 & 0 & & & & & & \\
\hline $\mathrm{OH}^{-}$ & $\mathrm{H}_{2} \mathrm{O}=\mathrm{OH}^{-}+\mathrm{H}^{+}$ & 3.5 & 0 & 293.29 & 0.1361 & -10576.9 & -123.73 & 0 & $-6.996 \mathrm{e}-5$ \\
\hline $\mathrm{HCO}_{3}^{-}$ & $\mathrm{CO}_{3}^{2-}+\mathrm{H}^{+}=\mathrm{HCO}_{3}^{-}$ & 5.4 & 0 & 107.89 & 0.0325 & -5151.8 & -38.93 & 563713.9 & \\
\hline $\mathrm{CO}_{2}$ & $\mathrm{CO}_{3}^{2-}+2 \mathrm{H}^{+}=\mathrm{CO}_{2}+\mathrm{H}_{2} \mathrm{O}$ & - & - & 464.20 & 0.0934 & -26986.2 & -165.76 & 2248628.9 & \\
\hline $\mathrm{CO}_{2(\mathrm{~g})}$ & $\mathrm{CO}_{2}=\mathrm{CO}_{2}$ & - & - & 119.87 & $2.19 \mathrm{e}-2$ & -7337.8 & -44.77 & 669371 & \\
\hline
\end{tabular}

Table 2. Parameter values for network 1 (Eqs. (16)-(19)). Parameter values are for illustrative purpose.

\begin{tabular}{|c|c|c|c|}
\hline Symbol & Parameter description & Value & Unit \\
\hline$i_{\mathrm{F}}$ & Addition of fresh organic matter & 0.0015 & $\mathrm{gC} / \mathrm{d} / \mathrm{dm}^{3}$ bulk \\
\hline$k_{\mathrm{B}}$ & Decay rate for biomass pool & $8.5 \times 10^{-3}$ & $1 / \mathrm{d}$ \\
\hline$r_{\mathrm{SOM}-\mathrm{P} 1 \rightarrow \mathrm{P} 2}$ & Transformation factor from SOM-P1 to SOM-P2 & 0.1 & - \\
\hline$r_{\mathrm{SOM}-\mathrm{P} 1 \rightarrow \mathrm{B}}$ & Transformation factor from SOM-P1 to B & 0.3 & - \\
\hline$r_{\mathrm{SOM}-\mathrm{P} 1 \rightarrow \mathrm{I}}$ & Transformation factor from SOM-P1 to I & 0.6 & - \\
\hline$r_{\mathrm{SOM}-\mathrm{P} 2 \rightarrow \mathrm{B}}$ & Transformation factor from SOM-P2 to B & 0.4 & - \\
\hline$r_{\mathrm{SOM}-\mathrm{P} 2 \rightarrow \mathrm{I}}$ & Transformation factor from SOM-P2 to I & 0.6 & - \\
\hline$\rho_{\mathrm{b}}$ & Bulk density & 1.43 & $\mathrm{~kg} / \mathrm{dm}^{3}$ bulk \\
\hline$k_{\mathrm{SOM}-\mathrm{P} 1}$ & Rate constant for SOM-P1 degradation & $3.00 \times 10^{-2}$ & $1 / \mathrm{d}$ \\
\hline$k_{\text {SOM-P2 }}$ & Rate constant for SOM-P2 degradation & $5.00 \times 10^{-3}$ & $1 / \mathrm{d}$ \\
\hline
\end{tabular}

Table 3. Parameter values for network 2 (Eqs. (24)-(30)). Parameter values are for illustrative purpose.

\begin{tabular}{|c|c|c|c|}
\hline Symbol & Parameter description & Value & Unit \\
\hline$i_{\mathrm{F}}$ & Addition of fresh organic matter & 0.0015 & $\mathrm{gC} / \mathrm{d} / \mathrm{dm}^{3}$ bulk \\
\hline$k_{\mathrm{B}}$ & Decay rate for biomass pool & $8.5 \times 10^{-3}$ & $\mathrm{gC} / \mathrm{d} / \mathrm{dm}^{3}$ bulk \\
\hline$r_{\mathrm{SOM}-\mathrm{P} 1 \rightarrow \mathrm{P} 2}$ & Transformation factor from SOM-P1 to SOM-P2 & 0.1 & - \\
\hline$r_{\mathrm{SOM}-\mathrm{P} 1 \rightarrow \mathrm{B}}$ & Transformation factor from SOM-P1 to B & 0.3 & - \\
\hline$r_{\mathrm{SOM}-\mathrm{P} 1 \rightarrow \mathrm{I}}$ & Transformation factor from SOM-P1 to I & 0.55 & - \\
\hline$r_{\mathrm{SOM}-\mathrm{P} 1 \rightarrow \mathrm{L}}$ & Transformation factor from SOM-P1 to SOM-L & 0.05 & - \\
\hline$r_{\mathrm{SOM}-\mathrm{P} 2 \rightarrow \mathrm{B}}$ & Transformation factor from SOM-P2 to B & 0.4 & - \\
\hline$r_{\mathrm{SOM}-\mathrm{P} 2 \rightarrow \mathrm{I}}$ & Transformation factor from SOM-P2 to I & 0.5 & - \\
\hline$r_{\mathrm{SOM}-\mathrm{P} 2 \rightarrow \mathrm{L}}$ & Transformation factor from SOM-P2 to SOM-L & 0.1 & - \\
\hline$r_{\mathrm{SOM}-\mathrm{L} \rightarrow \mathrm{B}}$ & Transformation factor from SOM-P2 to B & 0.1 & - \\
\hline$r_{\mathrm{SOM}-\mathrm{L} \rightarrow \mathrm{I}}$ & Transformation factor from SOM-P2 to I & 0.9 & $\mathrm{dm}^{3} / \mathrm{gC}$ \\
\hline$K_{\mathrm{L}}$ & Binding affinity of DOM & 5 & $\mathrm{gC} / \mathrm{dm}^{3}$ bulk \\
\hline$S_{\max }$ & Binding capacity for DOM & 0.4 & $\mathrm{~kg} / \mathrm{dm}^{3}$ \\
\hline$\rho_{\mathrm{b}}$ & Bulk density & 1.43 & $d^{-1}$ \\
\hline$k_{\text {sor }}$ & First-order kinetic sorption term & 0.05 & \\
\hline$k_{\mathrm{SOM}-\mathrm{P} 1}$ & Rate constant for SOM-P1 degradation & $3.0 \times 10^{-2}$ & $1 / \mathrm{d}$ \\
\hline$k_{\mathrm{SOM}-\mathrm{P} 2}$ & Rate constant for SOM-P2 degradation & $5.0 \times 10^{-3}$ & $1 / \mathrm{d}$ \\
\hline$k_{\mathrm{SOM}-\mathrm{L}}$ & Rate constant for SOM-L degradation & $2.0 \times 10^{-6}$ & $1 / \mathrm{d}$ \\
\hline
\end{tabular}

Table 4. Initial organic matter pools.

\begin{tabular}{lll}
\hline Organic Pool & Value & Unit \\
\hline SOM-P1 & $1.75 \times 10^{-4}$ & $\mathrm{kgC} / \mathrm{kg}$ soil \\
SOM-P2 & $7.00 \times 10^{-5}$ & $\mathrm{kgC} / \mathrm{kg}$ soil \\
SOM-L1 $^{*}$ & 0.019 & $\mathrm{gC} / \mathrm{dm}^{3} \mathrm{bulk}$ \\
B & $7.00 \times 10^{-5}$ & $\mathrm{kgC} / \mathrm{kg}$ soil \\
DOM $^{\$}$ & 0.01 & $\mathrm{gC} / \mathrm{dm}^{3}$ soil \\
\hline
\end{tabular}

Table 5. Soil hydraulic parameters for the van Genuchten (1980) soil hydraulic functions, solute transport parameters, and plant uptake parameters (for the S-shape water uptake reduction model - see the HYDRUS-1D manual for more information Simunek et al. (2013)) for single porosity model implementation.

\begin{tabular}{llcc}
\hline Symbol & Parameter description & Value & Unit \\
\hline$\theta_{\mathrm{r}}$ & Residual water content & 0.08 & $\mathrm{dm}^{3} / \mathrm{dm}^{3}$ \\
$\theta_{\mathrm{s}}$ & Saturated water content & 0.45 & $\mathrm{dm}^{3} / \mathrm{dm}^{3}$ \\
$\alpha$ & Shape parameter of the water retention function & 0.05 & $\mathrm{~cm}^{-1}$ \\
$n$ & Shape parameter of the water retention functions & 1.6 & - \\
$K_{\mathrm{s}}$ & Saturated hydraulic conductivity & 25 & $\mathrm{~cm} \mathrm{day}^{-1}$ \\
$D^{\mathrm{w}}$ & Diffusion coefficient in the aqueous phase & 2 & $\mathrm{~cm}^{2} \mathrm{day}^{-1}$ \\
$D^{\mathrm{a}}$ & Diffusion coefficient in the air phase & 20,000 & $\mathrm{~cm}^{2} \mathrm{day}^{-1}$ \\
$\lambda$ & Dispersivity & 10 & $\mathrm{~cm}^{-}$ \\
$P_{50}$ & Pressure head at which 50\% reduction in water uptake occur & -500 & $\mathrm{~cm}$ \\
$P_{3}$ & Exponent in the root water uptake response function & 3 & - \\
\hline
\end{tabular}

